\title{
THE
}

\section{Albumin protein coronas render nanoparticles surface active: consonant interactions at air-water and at lipid monolayer interfaces}

Nasim Ganji

University of Rhode Island

Geoffrey D. Bothun

University of Rhode Island, gbothun@uri.edu

Follow this and additional works at: https://digitalcommons.uri.edu/che_facpubs

The University of Rhode Island Faculty have made this article openly available. Please let us know how Open Access to this research benefits you.

This is a pre-publication author manuscript of the final, published article.

Terms of Use

This article is made available under the terms and conditions applicable towards Open Access Policy Articles, as set forth in our Terms of Use.

\section{Citation/Publisher Attribution}

Ganji, N. \& Bothun, G. D. (2021). Albumin protein coronas render nanoparticles surface active: consonant interactions at air-water and at lipid monolayer interfaces. Environ. Sci.: Nano, 8(1), 160-173.

https://doi.org/10.1039/D0EN00934B

Available at: https://doi.org/10.1039/D0EN00934B

This Article is brought to you for free and open access by the Chemical Engineering at DigitalCommons@URI. It has been accepted for inclusion in Chemical Engineering Faculty Publications by an authorized administrator of DigitalCommons@URI.For more information, please contact digitalcommons-group@uri.edu. 


\title{
Albumin protein coronas render nanoparticles surface active: Consonant interactions at air-water and at lipid monolayer interfaces
}

Nasim Ganji ${ }^{1}$ and Geoffrey D. Bothun ${ }^{1, *}$

${ }^{1}$ Department of Chemical Engineering, University of Rhode Island, 303 Fascitelli Engineering

Building, 2 East Alumni Ave, Kingston, RI 02881, United States

*Corresponding author. Tel: +1-401-874-9518, E-mail: gbothun@uri.edu

\section{Table of Contents Entry}

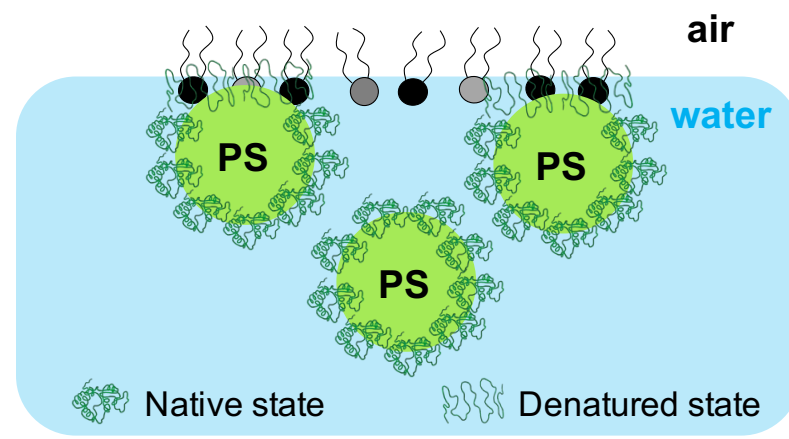

Albumin denaturing yields an additional driving force for protein corona-modified nanoparticles to adhere to biological interfaces that can be revealed a priori by modeling adsorption kinetics.

\begin{abstract}
Protein coronas are known to alter the physicochemical properties, colloidal stability, and biological fate of nanoparticles. Using human serum albumin (HSA) and polystyrene nanoparticles (NPs) with anionic or cationic surface chemistries, we show that protein coronas also govern the surface activity of PS nanoparticles as well as their interactions with a model red blood cell (RBC) lipid monolayer. The adsorption kinetics of bare nanoparticles (no corona) and nanoparticles with a hard corona $(\mathrm{HC})$ at an air-water interface were well-described theoretically,
\end{abstract}


which revealed that the adsorption energy was greater with the corona due to hydrophobic interactions that were enhanced with protein denaturing. Corona complexation increased the concentration of nanoparticles at the interface and led to the formation of interfacial aggregates. Despite clear differences in monolayer structure, the compressibility of PS-HC monolayers was similarly to free HSA, indicating that conformational changes associated with the protein were not restricted in a hard corona. The intrinsic behavior of the proteins driving the surface activity and compressibility of the complexes at an air-water interface was also observed at an air-lipid (RBC)-water interface. In this case the lipid monolayer acted as a barrier and reduced the interface concentration of bare nanoparticles. However, with a corona the nanoparticles penetrated into the monolayer and led to the formation of NP-HC-lipid 'pillars' that extended into air. Our results suggest that nanoparticle surface activity, and changes in surface activity due to corona formation, are insightful parameters to predicting nanoparticle-membrane interactions, complementing the conventional view that electrostatic forces are dominant.

\section{Introduction}

The environmental concentration of polymeric particles continues to increase due to the significant amount of disposed plastic waste. ${ }^{1-3}$ Plastics weather and degrade over time into micro- $(<5 \mathrm{~mm})$ and nano- $(<100 \mathrm{~nm})$ plastics, ${ }^{4-7}$ which pose a threat both to environmental and human health. ${ }^{6-15}$ Small plastic particles are ingested by organisms that are at the bottom of the food-chain and may bioaccumulate. ${ }^{1}$ It is estimated that humans consume 74,000 to 120,000 microplastic particles on average per year through ingestion and inhalation. ${ }^{16}$ The potential adverse health effects associated with these materials is analogous to those observed with engineered nanoparticles (ENPs). ${ }^{17-19}$ Toxicological studies conducted in vitro and in vivo have 
demonstrated that polymeric ENPs can translocate across living cells to the lymphatic and/or circulatory system, ${ }^{20,21}$ accumulate in secondary organs, ${ }^{22}$ and adversely impact the immune system. $^{23-25}$

Nanoparticle cellular uptake begins with particle adhesion to the cell surface and subsequent interactions with lipids and other components of the cell membrane. The interfacial and biophysical forces that modulate this process can be examined using lipid bilayers or monolayers as model cell membranes. ${ }^{26-35}$ Two main advantages of model membranes are that (1) the lipid composition and structure can be precisely controlled, thereby capturing essential biophysical aspects of cell membranes, and (2) the membrane organization and disruption can be measured directly using techniques that are not amenable to living cells. ${ }^{19}$ While model systems have been used extensively to study ENP-membrane interactions, ${ }^{17,19,36}$ few studies that have examined the effect of a biomolecular corona on these interactions. The biomolecular corona ultimately determines the biological identity of an ENP. ${ }^{37-42}$

Upon encountering biological fluids such as blood, nanoparticles are covered by biomolecules, notably proteins, that form a corona. ${ }^{43,44}$ The corona is composed of a tightly bound, but not completely irreversibly adsorbed layer of biomolecules (the "hard" corona or HC) that is surrounded by a more loosely bound and rapidly exchanging layer of biomolecules (the "soft" corona or SC). ${ }^{45}$ The formation of a corona has been reported for several nanoparticles, including polystyrene. ${ }^{37,46-49}$ The amount, composition, and orientation of biomolecules present in the corona strongly influence NPs adsorption, distribution, and elimination in biological systems, and governs their interactions with cellular membranes. ${ }^{50-52}$ Despite the importance of the biomolecular corona in dominating nanoparticle interactions at biological interfaces, the 
influence of protein corona formation on nanoparticle behavior at biological membranes has only recently begun to receive attention. ${ }^{53}$

Within the context of nanoparticle-membrane interactions, some studies have demonstrated increased adhesion and uptake for serum incubated ENPs relative to serum-free conditions, ${ }^{54-56}$ while other studies have shown the opposite - reduced adhesion and uptake after incubation in serum. ${ }^{57-62}$ For instance, Lesniak et al ${ }^{62}$ have examined the adhesion of polystyrene and silica NPs to the cell membrane and have shown that the presence of biomolecular corona strongly reduces nanoparticle adhesion (and uptake) by weakening nonspecific interactions between NPs and the cell membrane. On the other hand, Chithrani et $a^{56}$ have reported a greater uptake for gold NPs when a serum protein corona is present. Detailed studies are needed to determine the surface activity of native and corona-modified nanoparticles, how this activity governs interactions with lipid interfaces, and how surface and interfacial activity relate to the physicochemical properties of the NPs and the formed corona.

We propose that the surface activity of corona-modified nanoparticles (i.e. at the airwater interface), which is governed by the amphiphilicity of the corona coating and the ability of the corona proteins to adsorb and undergo conformational changes at the interface, is directly related to the extent of nanoparticle adsorption at lipid interfaces. This would provide a new parameter, particle surface activity, to determine $a$ priori the potential interactions with biological membranes. To test this hypothesis, we have examined the response of a human red blood cell (RBC) model membrane, deployed as a lipid monolayer, to the adhesion of polystyrene (PS) nanoparticles with anionic or cationic surface chemistries, and modified with a human serum albumin (HSA) corona. The Langmuir-Blodgett technique, combined with fluorescence and Brewster angle microscopy, was used to measure the kinetics of PS NP 
adhesion and the monolayer response, and to identify the properties of the particles and coronas that contribute to the activity at air-water and air-lipid-water interfaces.

\section{Experimental}

Materials. All materials were used as received unless otherwise noted. 1-Palmitoyl-2-oleoyl-snglycero-3-phosphocholine (POPC), 1-palmitoyl-2-oleoyl-sn-glycero-3-phosphoethanolamine (POPE), egg sphingomyelin (SM), and 1,2-dioleoyl-sn-glycero-3-phosphoethanolamine-N(lissamine rhodamine B sulfonyl) (Liss Rhod PE) were purchased from Avanti Polar Lipids (Alabaster, AL). Unmodified (PS) and carboxylate-modified fluorescent polystyrene (PS$\mathrm{COOH}$ ) NPs were purchased form Polysciences Inc. (Warrington, PA). Amine-modified fluorescent polystyrene (PS-NH) NPs and human serum albumin (HSA, lyophilized powder, essentially fatty acid free) were purchased from Sigma Aldrich. NPs were purified before monolayer experiments by centrifugation and rinsing. Phosphate buffer saline (PBS, pH 7.4) was purchased from Fisher Scientific (Waltham, MA). Chloroform $\left(\mathrm{CHCl}_{3},>99.8 \%\right.$ ), acetone $\left(\mathrm{C}_{3} \mathrm{H}_{6} \mathrm{O},>99.5 \%\right)$, and ethanol $\left(\mathrm{C}_{2} \mathrm{H}_{6} \mathrm{O},>99.5 \%\right)$ from Fisher Scientific (Waltham, MA) were used as solvents for making stock solutions of the lipids and cleaning the Langmuir trough. Deionized (DI) ultra-filtered water was obtained from a Millipore Direct-Q3 UV purification system (Billerica, MA) at $18.2 \mathrm{~m} \Omega$ resistance and $\mathrm{pH} 6.5$.

The model monolayer was composed of lipids naturally occurring in the outer layer of human erythrocytes; ${ }^{63-67}$ POPC:POPE:SM at the molar ratio 44.9:12:43.1, respectively. A small quantity ( $1 \mathrm{~mol} \%$ ) of rhodamine-conjugated phosphatidylethanolamine (PE) lipid was added to this mixture as a fluorescent probe to label model membrane. 
Formation of nanoparticle-hard corona complexes. NP-HC complexes were prepared following the procedure reported for carboxylate-modified PS NPs by Silvio et al. ${ }^{68,69} \mathrm{NP}$ solutions were added to $1.5 \mathrm{~mL}$ microcentrifuge tubes to attain final NP concentrations of $1 \mathrm{mg}$ $\mathrm{mL}^{-1}$. HSA (5\% in PBS) was added to the microcentrifuge tubes, and the tubes were incubated at $37^{\circ} \mathrm{C}$ for $1 \mathrm{~h}$. The tubes were subsequently centrifuged three times $\left(18,000 \mathrm{~g}, 4^{\circ} \mathrm{C}\right)$ with a PBS solution wash between each centrifugation step. The sedimented NPs were re-dispersed in PBS to isolate the NP-HC complexes.

Characterization of nanoparticles and nanoparticle-hard corona complexes. NPs and NP-HC complexes were characterized using transmission electron microscopy (TEM; JEOL JEM$2100 \mathrm{~F}$ ) operating at $200 \mathrm{kV}$ and a Malvern Zetasizer Nano ZSX for their core radius, and hydrodynamic radius and zeta (६) potentials, respectively. The average size of PS NPs was determined by analyzing multiple TEM images with ImageJ software $(n>50) \cdot{ }^{70}$ To measure the average $\zeta$-potentials and hydrodynamic diameter $\left(d_{h}\right)$ of the NPs, the as-received particles were diluted in PBS and analyzed at $25^{\circ} \mathrm{C}$. The values reported are based on triplicate measurements of three different samples. Adsorption of HSA on PS NPs were visualized by performing negative-staining TEM. ${ }^{71-73}$ One drop of the diluted NP-HC solution was placed on a carbon coated grid and blotted with filter paper, after which a small aliquot of $2 \%$ uranyl acetate was placed on the grid and was dried thoroughly at room temperature before imaging.

NP-HC complexes were analyzed further using thermogravimetric analysis (TGA; TA Q500, New Castle, DE) for their protein content. The amount of HSA adsorbed on the NPs was determined by measuring the weight loss of the NP-HC complexes in the range of $200-550{ }^{\circ} \mathrm{C}$ due to protein degradation, ${ }^{74}$ and subtracting it from the weight loss of the NPs over the same 
temperature range. Heating was performed in a platinum crucible under a nitrogen flow $(60 \mathrm{~mL}$ $\min ^{-1}$ ) at a rate of $10^{\circ} \mathrm{C} \min ^{-1}$ up to $1000{ }^{\circ} \mathrm{C}$.

Monolayer surface pressure measurements. Monolayers experiments were conducted at $23^{\circ} \mathrm{C}$ as previously described. ${ }^{31}$ Monolayers were prepared in Teflon ${ }^{\circledR}$ Langmuir-Blodgett trough (KN2002, KSV NIMA, Biolin Scientific Inc., Linthicum Heights, MD) filled with PBS by spreading dissolved lipids in chloroform at the air-water interface and allowing $45 \mathrm{~min}$ for the chloroform to evaporate. Isotherms were generated for a single compression/expansion cycle at a barrier rate of $2 \mathrm{~cm}^{2} \mathrm{~min}^{-1}$ and the interfacial tension $(\gamma)$ or surface pressure $\left(\pi=\gamma_{0}-\gamma\right.$, where $\gamma_{0}=72.5 \mathrm{mN} \mathrm{m}^{-1}$ ) was measured using paper Wilhelmy plates. The total area of the trough during this cycle ranged from roughly $70-240 \mathrm{~cm}^{2}$. After recording an isotherm, the trough was set to maintain a constant initial surface pressure $\left(\pi_{0}=30 \mathrm{mN} \mathrm{m}^{-1}\right)$. Once the monolayer stabilized and $\pi_{0}$ remained constant, the barrier positions were fixed at the corresponding interfacial area and HSA (22.75 mg L-1), NPs $\left(10 \mathrm{mg} \mathrm{L}^{-1}\right)$, or NP-HC $\left(10 \mathrm{mg} \mathrm{L}^{-1}\right)$ complexes were added to the subphase by injecting them behind the barriers without disrupting the monolayer. The NP and NP-HC subphase concentrations correspond to the amount needed to provide excess surface coverage based on the PS NP cross sectional area at a monolayer surface area of $240 \mathrm{~cm}^{2}$. To determine the adsorption kinetics of NPs and NP-HC complexes at the lipidwater interface, dynamic changes in $\gamma$, expressed as $\gamma-\gamma_{0}$, were monitored over 400-600 min. The same monolayer experiments were conducted in the absence of lipid monolayers to determine the surface activity and adsorption kinetics of NPs and NP-HC complexes at the airwater interface. Sample volumes of $2 \mathrm{~mL}$ were removed from the Langmuir trough subphase at the end of the monolayer experiments to determine the concentration of PS NPs by UV-vis 
spectroscopy based on the maximum peak height at a wavelength of $240 \mathrm{~nm}$ after baseline subtraction. All experiments were conducted at least in duplicate.

The morphology of the monolayers was visualized using fluorescence and Brewster angle microscopy. For fluorescence microscopy, the Langmuir films were transferred to plasma cleaned glass slides using the Langmuir-Blodgett (LB) deposition technique at constant surface pressures of 10, 20, or $30 \mathrm{mN} \mathrm{m}^{-1}$ at a deposition rate of $0.5 \mathrm{~mm} \mathrm{~min}^{-1} .{ }^{75}$ A CytoViva microscope equipped with a Dual Mode Fluorescent Module was used to obtain fluorescent images of the deposited film. Brewster Angle Microscopy (BAM) was used to enable real-time observation of monolayers at the air-water interface in a Langmuir trough. BAM provides information on homogeneity, phase behavior and the film morphology by detecting changes in the refractive index of the water surface in the presence of surfactants or surface-active molecules.

\section{Results and Discussion}

Characterization of nanoparticles and nanoparticle-corona complexes. The average diameter (d) of the unmodified, carboxylate- and amine-modified PS NPs was $98 \pm 9 \mathrm{~nm}$ based on TEM analysis (Figure S1). Similar hydrodynamic diameters $\left(d_{h}\right)$ were measured for all three NPs (Fig. 1A), which was consistent with the average particle diameter measured by TEM. The carboxylate PS-COOH NPs and the unmodified PS NPs were negatively charged, with the surface charge on the unmodified particles due to an anionic surfactant coating (Figure 1B). The amine PS-NH NPs were cationic owing to the secondary amine groups. 

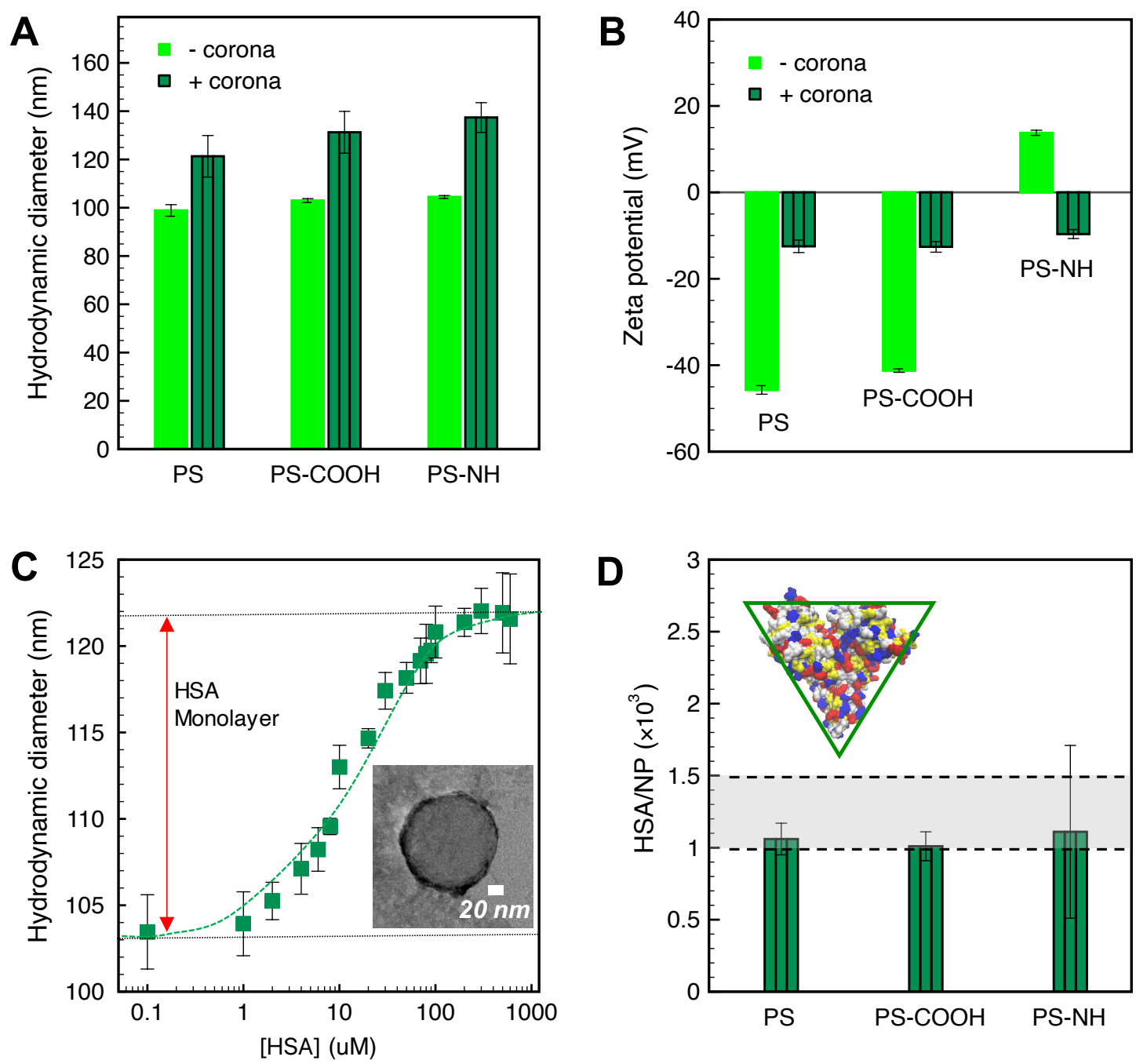

Figure 1. (A) Average hydrodynamic diameters $\left(d_{h}\right)$, (B) the $\zeta$-potential of NPs and NP-HC complexes, and (C) the increase in NP $d_{h}$ upon adsorption of HSA (inset: representative micrograph of PS-HC complexes; HSA is negatively stained). Samples were prepared in $\mathrm{pH} 7.4$ PBS and the reported values are based on triplicate measurements of three different samples. (D) The calculated amounts of HSA comprising the protein corona for the different NP-HC complexes (inset: schematic of the dimensions of the HSA as an equilateral triangular prism ${ }^{76}$ ). Error bars correspond to one standard deviation for triplicate experiments. 
The changes in $\zeta$-potential and $d_{h}$ of the particles (Figures 1A, B) with a protein corona provided direct evidence of the complexation of PS NPs by HSA. Figure 1C shows the increase of PS NPs hydrodynamic diameter upon HSA incubation for concentrations ranging from 0.1 to $600 \mu \mathrm{M}$ HSA. From these results a concentration of $300 \mu \mathrm{M}$ HSA was assumed to saturate the NP surface and form a close-packed protein monolayer. ${ }^{71}$ The increase in $d_{h}$ due to corona formation was $\sim 20 \mathrm{~nm}$ and was common to all three PS NPs corresponding to a shell thickness of $\sim 10 \mathrm{~nm}$ (Figure 1A), which was similar to the z-averaged hydrodynamic diameter measured for HSA $(10.7 \pm 2.3 \mathrm{~nm})$. An HSA shell thickness of $7 \pm 1 \mathrm{~nm}$ for PS-HC complexes was further shown by negative-staining TEM imaging (Figure 1C, inset). Upon protein complexation, the $\zeta-$ potential of the particles became either negative, in the case of amine-modified PS NPs, or less negative for unmodified and carboxylate-modified PS NPs, approaching the value measured for HSA in PBS $(-9.9 \pm 1.2 \mathrm{mV}$ ) (Figure 1B). These data indicate that NPs form complexes with HSA, and that complexation occurred for all three PS nanoparticles with different surface chemistries.

Considering the dimensions of HSA $\left(76 \times 76 \times 28 \AA^{3}\right)^{76}$ and the nanoparticle surface area $\left(\pi d_{h}^{2}\right)$, we estimated that $1.0 \times 10^{3}$ to $1.5 \times 10^{3}$ HSA molecules (based on flat or edge-on binding configurations, respectively) are required to form a close-packed monolayer of protein corona. This was confirmed by TGA where $1.0 \times 10^{3}$ to $1.1 \times 10^{3}$ HSA per NP were measured at saturation (Figure 1D), which is in good agreement with our calculations for HSA binding.

Insight into the mechanism of HSA binding and corona formation can be gained from the protein surface charge distribution and the Debye screening length $\left(\kappa^{-1}\right)$ at physiological salt concentration in PBS. The structure of HSA at $\mathrm{pH} 7.4$ was determined computationally and shows the coexistence of acidic (blue; aspartic acid, glutamic acid) and basic (red; arginine, 
histidine, lysine) amino acid residues on the protein surface (Figure S2). Hydrophobic (silver) and polar (yellow) residues are also shown. Despite the net negative charge of HSA, positive and negative amino acids are distributed on its surface and provide local binding sites for opposite charges. Furthermore, $\kappa^{-1}$ is approximately $0.8 \mathrm{~nm}$ (150 mM monovalent ions), which means that the proteins and NPs come into close contact before experience electrostatic interactions. At this length scale van der Waals attraction was assumed to be the driving force for HSA adsorption, aided by the mixed charge distribution on the protein surface.

\section{Dynamic interfacial tension of nanoparticles and nanoparticle-corona complexes at the air-}

water interface. Dynamic adsorption behavior can be described by a three-stage process as depicted in Figures 2A-C, respectively. During stage 1, $\gamma$ decreases slowly due to the adsorption of individual particles to a pristine interface. As the excess surface concentration of NPs increases during stage $2, \gamma$ decreases more rapidly. As $t \rightarrow \infty$ during stage 3 the interface approaches maximum coverage and the rate of NP surface adsorption decreases due to a steric barrier. During this stage $\gamma$ plateaus, reflecting a pseudo-equilibrium condition.

As shown in Figures 2A-C, bare NPs were not appreciably surface active with a maximum change in interfacial tension of approximately $-1.5 \mathrm{mN} \mathrm{m}^{-1}$ that we attribute to the charged surface ligands. HSA corona complexation rendered the NPs surface active due to hydrophobic interactions at the air-water arising from the hydrophobic amino acid residues of the proteins interface. ${ }^{91,92}$ Similar surface activities, or reductions in interfacial tension, were observed for all three NP-HC complexes and the difference between the pseudo-equilibrium interfacial tension at the end of stage 3 with and without a corona was approximately $-7 \mathrm{mN} \mathrm{m}^{-1}$. 

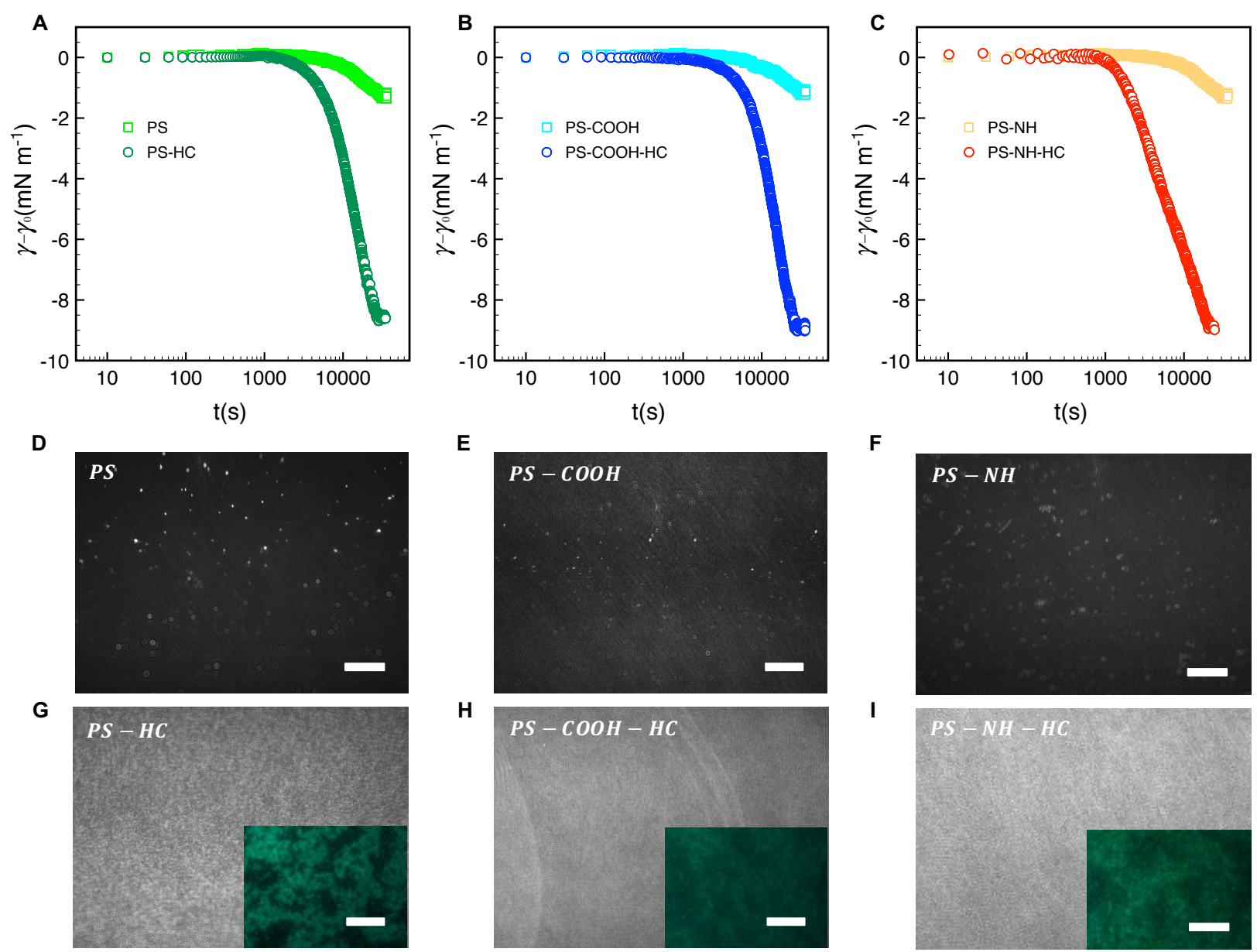

Figure 2. Dynamic changes in surface tension for (A) PS, (B) PS-COOH, and (C) PS-NH nanoparticles before and after complexation with HSA plotted in a semi-logarithm scale. Representative fluorescence microscopy (scale bars $=20 \mu \mathrm{m}$ ) and BAM images (scale bars $=300$ $\mu \mathrm{m}$ ) are shown for (D) PS, (E) PS-COOH, and (F) PS-NH NP and (G) PS-HC, (H) PS-COOH$\mathrm{HC}$, and (I) PS-NH-HC complexes at the air-water interface at pseudo-equilibrium conditions $(t \rightarrow \infty)$.

The morphology and packing of NP and NP-HC Langmuir films at the interface were examined at the pseudo-equilibrium condition (stage 3) using fluorescence microscopy and BAM. Bare NPs adsorbed at the interface and formed fractal aggregates on the micrometer scale 
and larger due to attractive van der Waals and capillary interactions ${ }^{79}$ (Figures 2D-F; Figures $\mathrm{S} 3 \mathrm{~A}, \mathrm{~B})$. For NP-HC complexes, the formed monolayers were thicker based on BAM reflectance (Figures 2G-I) and comprised of denser aggregates that we attribute to a combination of capillary interactions and interparticle attraction driven by the hydrophobic interactions between coronas with denatured proteins at the air-water interface (Figures $2 \mathrm{G}-\mathrm{I}$ inset; Figures S3C, B).

The subphase concentrations of PS NPs were analyzed by UV-vis spectroscopy at the end of stage 3 to further quantify the extent of NP and NP-HC adsorption at the air-water interface. The NP surface concentrations, $\Gamma$, were determined by mass balance as $\Gamma=\left(c_{i}-\right.$ $\left.c_{e q}\right)_{b} V\left(V_{N P} \rho_{P S} A\right)^{-1}$ where $\left(c_{i}-c_{e q}\right)_{b}$ is the change in bulk PS concentration from initial $\left(c_{i}\right)$ to pseudo-equilibrium $\left(c_{e q}\right), V_{N P}$ is the mean PS NP volume, $\rho_{P S}$ is the density of polystyrene, and $V$ and $A$ are the trough volume and area, respectively. For bare NPs, the surface concentrations reflect maximum fractional surface coverages $\left(\Theta_{\infty}\right)$ from 0.34 to 0.48 . The presence of a protein corona increased NP adsorption, and the surface excess concentration for all three types of NPHC complexes was similar at $\Gamma_{+ \text {corona }} \approx 15 \times 10^{13} \mathrm{NP} \mathrm{m}^{-2}$ (Figure 3 ). At this surface concentration $\Theta_{\infty} \approx 0.9$. The increase in adsorption a due to corona complexation was approximately $45 \%$ for PS-NH and PS-COOH, and $62 \%$ for unmodified PS. While the value of $\Theta_{\infty} \approx 0.9$ is near that for a hexagonally packed monolayer of spheres $(0.91)^{80}$, the microscopy analysis shows that the PS-HC layers were comprised of interfacial aggregates rather than a continuous monolayer. 

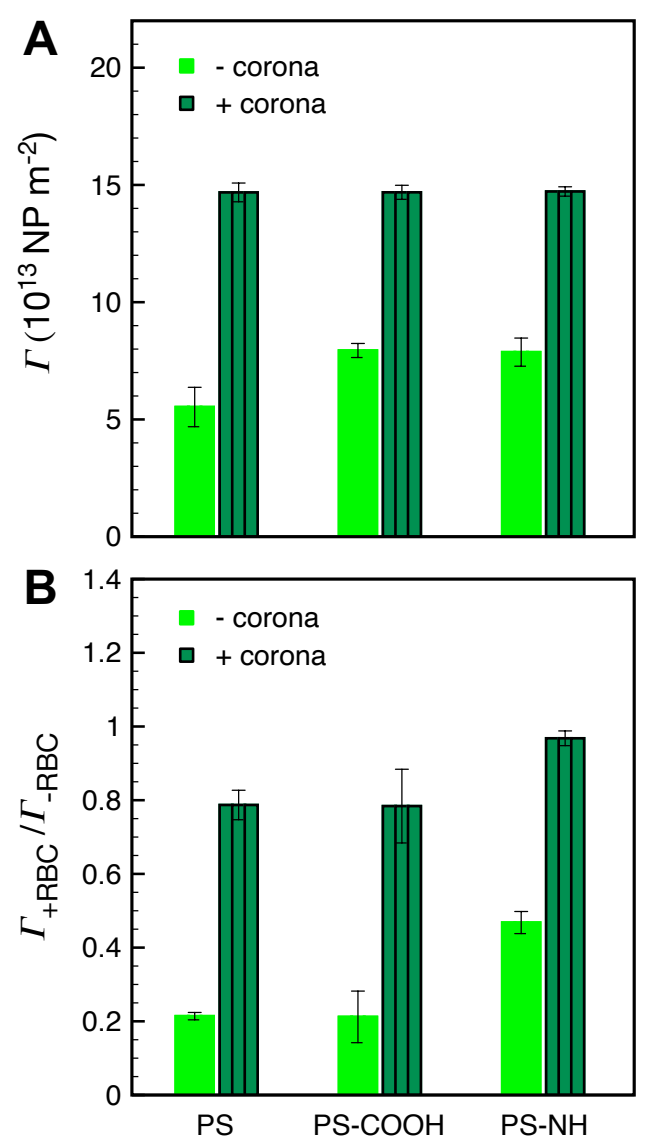

Figure 3. Surface concentration $\left(\Gamma, \mathrm{NP} \mathrm{m} \mathrm{m}^{-2}\right)$ of PS nanoparticles with and without a formed corona (- corona and + corona, respectively) (A) at the air-water interface and (B) at the air-lipidwater interface. Results in (B) show the change in concentration, $\Gamma_{+R B C} / \Gamma_{-R B C}$, when the RBC lipid layer is present relative to an air-water interface. Error bars represent one standard deviation of triplicate experiments.

\section{Adsorption kinetics of nanoparticles and nanoparticle-corona complexes at the air-water}

interface. The presence of a hard corona on PS nanoparticles leads to similar apparent surface activities (Figures 2A-C) and similar interfacial structures (Figures 2G-I), consistent with the view that formed protein coronas govern the physicochemical properties of nanoparticles. To 
determine if corona formation also leads to similar kinetics of NP adsorption, the dynamic interfacial tension results were analyzed using the model of Ward and Tordai. ${ }^{81}$ The following asymptotic equations have been employed to interpret data from the early $(t \rightarrow 0)$ and late $(t \rightarrow$ $\infty)$ times of NP adsorption.

At early times (stage 1), an individual NP that is adsorbing to the interface encounters a bare interface leading to a change in $\gamma$. Assuming there is no barrier to adsorption at this stage, particle diffusion to the interface is the rate-limiting step and the diffusion-controlled Ward and Tordai mechanism can be applied. ${ }^{81}$ Bizmark et al. ${ }^{82}$ modified the Ward and Tordai model to account for NPs larger than $10 \mathrm{~nm}$ with adsorption trapping energy exceeding $10^{3} k_{B} T$

$$
\gamma=\gamma_{0}-2 N_{A}|\Delta E| C_{0} \sqrt{\frac{D t}{\pi}}
$$

where, $N_{A}$ is Avogadro's number, $\Delta E$ is the trapping energy of a single particle at the interface, $D$ is the NP diffusion coefficient, and $C_{0}$ is the bulk molar concentration. The number of NPs adsorbed at the interface is significantly less than that remaining in the bulk and $C_{0}$ is assumed to be constant throughout the adsorption process. Surface coverage at any time during the adsorption process can be calculated from the measured interfacial tension ${ }^{82}$

$$
\frac{\Theta}{\Theta_{\infty}}=\frac{\gamma_{0}-\gamma}{\gamma_{0}-\gamma_{\infty}}
$$

where $\Theta$ is the surface coverage for a given $\gamma$, and $\gamma_{\infty}$ is the equilibrium interfacial tension. Measured values for $\Theta_{\infty}$ were used based on the excess PS surface concentrations at the end of adsorption process.

The stage 1 region in Figure 2A-C were defined by the range $\Theta=0$ to $0.3,{ }^{80}$ providing a basis for calculating $\gamma$ at $\Theta=0.3$ using equation (2). Considering the stage 1 adsorption energy 
as $|\Delta E|=\frac{\left(\gamma_{0}-\gamma_{\infty}\right) \pi r^{2}}{\Theta_{\infty}}$, effective diffusion coefficients, $D$, were determined based on equation (1) by linear regressions of $\gamma-\gamma_{0}$ vs. $t^{0.5}$. Table 1 reports the values of $D$ for NPs and NP-HC complexes, and compares them to diffusion coefficients predicted by the Stoke-Einstein equation $D_{S E}=\frac{k_{B} T}{6 \pi \mu r}$, where $r$ is the hydrodynamic radii of the particles and $\mu$ is the viscosity of water at room temperature. Values of $D$ and $D_{S E}$ differ by just 30 to $47 \%$, indicating that equation (1) is valid during the early times adsorption of particles from the bulk to the air-water interface.

Using $D_{S E}$ values, equation (1) was then used to calculate the stage 1 adsorption energy, $\left|\Delta E_{S 1}\right|$. As shown in Table 1 , the magnitude of the adsorption energy correlated with the $\zeta$ potential of the NPs where $\left|\Delta E_{S 1}\right|$ increased as the $\zeta$-potential became less negative (or more positive). This result is consistent with anionic NPs being electrostatically repelled from the airwater interface, which has been shown to have a negative surface potential. ${ }^{83,84}$

Unlike NP adsorption, two distinct stages with clearly different slopes were observed for NP-HC complexes when $\gamma-\gamma_{0}$ vs $t^{0.5}$ was plotted from $\Theta=0$ to 0.3 (Figures S4A, B). This is consistent with recent work by Tian et al. ${ }^{85}$ for the adsorption kinetics of poly(ethylene oxide) (PEO)-modified polystyrene NPs to air-water interfaces. As shown in Figure 2, although the transition between these two stages occurs at an earlier time for PS-NH-HC compared to PS-HC and PS-COOH-HC, no statistically significant difference in interfacial tension is observed at this transition point between the three types of NP-HC complexes. For stage 1, we calculated the diffusion coefficients and adsorption energies of NP-HC complexes as we did for bare NPs; using the slope of $\gamma-\gamma_{0}$ vs $t^{0.5}$ according equation (1). Values for $D$ and $D_{S E}$ are remarkably similar and confirm the effects of adsorbed coronas on increasing the hydrodynamic diameters and reducing diffusivity compared to the bare NPs. The effect of the corona can also be observed in $\left|\Delta E_{S 1}\right|$, with significantly greater values being measured for NP-HC complexes due to 
hydrophobic interactions at the air-water interface (i.e. greater thermodynamic driving force for particle trapping at the interface). The greatest driving force is observed for the particles where the corona is formed on cationic amine-modified PS, which also has a $\zeta$-potential closest to zero.

Table 1. Diffusion coefficients $\left(D_{S E}, D\right)$, stage 1 and stage 2 adsorption energies $\left(\left|\Delta E_{S 1}\right|\right.$ and $\left|\Delta E_{S 2}\right|$, respectively), and stage 3 adsorption constants $\left(k_{a}\right)$ associated with nanoparticle and nanoparticle-corona adsorption kinetics. Errors correspond to one standard deviation from triplicate experiments.

\begin{tabular}{|c|c|c|c|c|c|}
\hline & & & $\begin{array}{c}\text { Stage 1 } \\
\text { (Diffusion- } \\
\text { controlled) }\end{array}$ & $\begin{array}{c}\text { Stage } 2 \\
\text { (Protein } \\
\text { denaturing) }\end{array}$ & $\begin{array}{c}\text { Stage } 3 \\
\text { (Barrier- } \\
\text { controlled) }\end{array}$ \\
\hline & $\begin{array}{c}D_{S E} \\
\left(10^{-12} \mathrm{~m}^{2} \mathrm{~s}^{-1}\right)^{\mathrm{a}}\end{array}$ & $\begin{array}{c}D \\
\left(10^{-12} \mathrm{~m}^{2} \mathrm{~s}^{-1}\right)\end{array}$ & $\begin{array}{c}\left|\Delta E_{S 1}\right| \\
\left(10^{4} k_{B} T, \mathrm{~J}\right)\end{array}$ & $\left|\Delta E_{S 2}\right| /\left|\Delta E_{S 1}\right|$ & $\begin{array}{c}k_{a} \\
\left(10^{-6} \mathrm{~m} \mathrm{~s}^{-1}\right)\end{array}$ \\
\hline PS & $4.91 \pm 0.12$ & $7.92 \pm 0.78$ & $1.35 \pm 0.02$ & - & - \\
\hline PS-COOH & $4.73 \pm 0.29$ & $6.78 \pm 0.15$ & $1.81 \pm 0.05$ & - & - \\
\hline PS-NH & $4.63 \pm 0.35$ & $6.25 \pm 0.18$ & $2.61 \pm 0.02$ & - & - \\
\hline PS-HC & $3.99 \pm 0.30$ & $3.78 \pm 0.37$ & $8.11 \pm 0.19$ & 6.86 & $1.70 \pm 0.19$ \\
\hline PS-COOH-HC & $3.71 \pm 0.27$ & $3.31 \pm 0.18$ & $6.13 \pm 0.24$ & 7.43 & $1.51 \pm 0.93$ \\
\hline PS-NH-HC & $3.54 \pm 0.16$ & $4.54 \pm 0.93$ & $8.99 \pm 1.03$ & 11.39 & $5.83 \pm 0.42$ \\
\hline$H S A$ & $66.0 \pm 6.1$ & - & $14.64 \pm 0.95^{b}$ & 2.16 & - \\
\hline
\end{tabular}

a Standard deviation in $D_{S E}$ based measured standard deviations of hydrodynamic radii.

${ }^{\mathrm{b}}$ Unit of $10^{0} k_{B} T$.

At the end of stage 1 the surface coverage, $\Theta$, was less than 0.05 for the NP-HCs. Hence, for stage 2 we inferred that particle adsorption is also diffusion-controlled and that the Stokes-Einstein equation can be applied to estimate the diffusion coefficients of the NP-HCs. The adsorption energy during stage $2,\left|\Delta E_{S 2}\right|$, was calculated according to equation (1) (Table 1; reported as $\left.\left|\Delta E_{S 2}\right| /\left|\Delta E_{S 1}\right|\right)$ and was approximately 7- to 11-fold greater than for stage 1 . The 
observed two-stage transition for NP-HC complexes is attributed to initial particle diffusion (stage 1) followed by protein denaturing (stage 2 ) at the air-water interface. ${ }^{81}$ Protein denaturing, exposing hydrophobic residues at the air-water interface as the protein unfolds, led to significant reductions in interfacial tension accompanied by high adsorption energies.

As the interface becomes saturated $(t \rightarrow \infty$ and $\Theta>0.75),{ }^{82}$ the presence of adsorbed particles hinders additional particle attachment. Stage 3 adsorption kinetics can be described by introducing a blocking function to the long-time Ward and Tordai approximation to account for the adsorption barrier at high NP surface coverage ${ }^{86}$

$$
\begin{gathered}
\gamma=\gamma_{\infty}+\frac{K_{1}|\Delta E|}{\left(\pi r^{2}\right)^{2} N_{A} C_{0}} \sqrt{\frac{1}{D t}} \\
K_{1}=\Theta_{\infty} \sqrt{\frac{\Theta_{\infty}}{4.64 k_{a}}}
\end{gathered}
$$

where, $K_{1}$ is the dimensionless reaction coefficient, and $\underline{k_{a}}$ is the dimensionless adsorption constant. The adsorption constant, $k_{a}$, can be determined as, $k_{a}=\underline{k_{a}} D N_{A} C_{0} \pi r^{2}$.

For bare PS NPs $\Theta_{\infty} \leq 0.48$, indicating that adsorbing particles did not experience a crowded interface and the adsorption is diffusion-controlled at any time during the process. For NP-HC complexes, $k_{a}$ was calculated from the gradient of $\gamma-\gamma_{0}$ vs. $t^{-0.5}$ (shown for PS$\mathrm{COOH}-\mathrm{HC}$ in Figure S4C). The values of $k_{a}$ for all NP-HC complexes are listed in Table 1. PSNH-HC complexes have greater adsorption constant compared to unmodified and carboxylatemodified NP-HC complexes. The greater value of $k_{a}$ for PS-NH-HC denotes a faster rate of adsorption in stage 3, which is consistent with greater adsorption energies for particle attachment $\left(\left|\Delta E_{S 1}\right|\right)$ and protein denaturing $\left(\left|\Delta E_{S 2}\right|\right)$ for the amine-modified PS compared to the anionic nanoparticles. 


\section{Surface pressure-area isotherms of nanoparticles and nanoparticle-corona complexes at the}

air-water interface. The compressibility and structure of the interfacial layers were further examined through surface pressure-area $(\pi-A)$ isotherms and BAM. HSA alone shows the characteristic sigmoidal shape with a steep increase in $\pi$ (reduction in $\gamma$ ) upon initial compression as denatured proteins pack at the interface, followed by a transition near $\pi=12 \mathrm{mN}$ $\mathrm{m}^{-1}$ where hydrophilic residues are expelled from the interface due to steric hinderance (Figure 4A). ${ }^{87}$ Additional compression yields a second transition near $\pi=20 \mathrm{mN} \mathrm{m}^{-1}$ as the reconfigured proteins continue to pack. A maximum inverse compressibility modulus $\left(C^{-1}=A \frac{d \pi}{d A}\right)$, or resistance to packing, is observed at $40 \mathrm{mN} \mathrm{m}^{-1}$. The NP-HC complexes exhibit strikingly similar behavior; both transitions are observed and shape of the $C^{-1}$ vs. $A$ curves are nearly superimposable for PS-COOH-HC at the point of inflection (Figure 4A; position of maximum $C^{-1}$ ). PS-HC exhibited similar behavior (Figure S5A1). This similarity is not attributed to unbound HSA in NP-HC samples as we confirmed that there was no measurable unbound HSA after the separation step during corona formation, consistent with previous work showing that protein coronas are stable, exhibiting little protein desorption. ${ }^{71}$ These results demonstrate that HSA bound within a corona complex behaves similarly to unbound HSA at the air-water interface, which infers that the free energy change associated with surface activity and corresponding conformational changes competes with the attractive protein-particle interactions that lead to corona formation. Complexes formed with cationic PS NPs, PS-NH-HC (Figure S5B1), deviated slightly and exhibited a $C^{-1}$ that was $10 \mathrm{mN} \mathrm{m}^{-1}$ lower than HSA or the other NP-HC complexes. This reflects a lower resistance to compression that may be due to a greater preference for the proteins to remain in the NP-bound state as indicated by the stronger binding 
and denaturing energies determined from the kinetic analysis. The corona proteins (negatively charged) may also have resisted reconfiguration due to stronger electrostatic interactions with the positively charged particle surface.

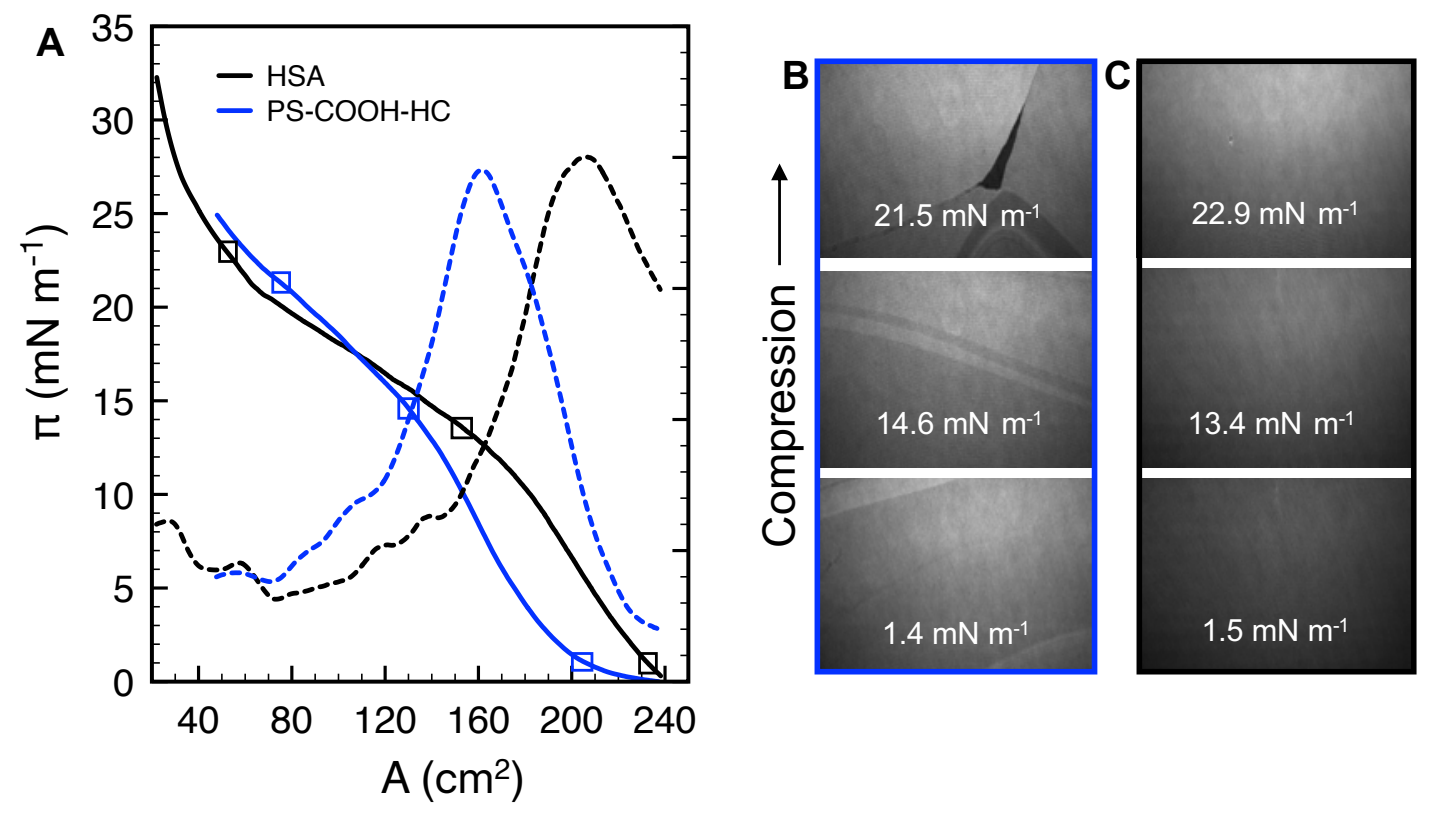

Figure 4. Surface pressure-area isotherms $(\pi-A)$ and corresponding inverse compressibility moduli $\left(C^{-1}\right)$ for HSA and the PS-COOH hard corona complexes (PS-COOH-HC) at the airwater interface. The open squares shown on the isotherms denote the conditions for BAM imaging shown in B. BAM images for HSA alone are shown in C.

BAM analysis of the films show thick NP-HC monolayers, based on reflectance, and a variety of lateral and clustered phases that span the compression range (Figures 4B; S5A2, B2). These phases are not observed for HSA alone (Figure 4C), though small differences in HSA film thickness were evident. At no point in the NP-HC isotherms were void spaces (black regions void of reflectance) observed, indicating the coexistence of dense and lean NP-HC regions. The exception to this is for PS-COOH-HC at high compression $\left(\pi=21.5 \mathrm{mN} \mathrm{m}^{-1}\right.$; Figure 4B) where a defect is seen in the layer. It is interesting to note that the apparent thickness (reflectance) of the 
NP-HC layers did not change significantly with compression as shown for HSA. To accommodate the NP-HC layers with compression some of the particles must have been displaced into the aqueous phase without forming wrinkles, at least at the length scales observable by BAM imaging.

Nanoparticle and nanoparticle-corona complexes at the air-lipid-water interface. We now compare the behavior of NPs and NP-HC complexes at an air-water interface to when a model $\mathrm{RBC}$ lipid monolayer is present. Dynamic changes in interfacial tension were determined as $\gamma-\gamma_{L}$, where $\gamma_{L}$ is the initial interfacial tension at air-lipid-water interface $\left(\gamma_{L}=42.5 \mathrm{mN} \mathrm{m}^{-1}\right.$ corresponding to an initial surface pressure, $\pi=\gamma_{0}-\gamma_{L}$, of $30 \mathrm{mN} \mathrm{m}^{-1}$ ). At this surface pressure the compressed monolayer has an average area per lipid, $A$, of $63 \AA^{2}$ molecule $e^{-1}$ with coexisting liquid-expanded (LE; rich in POPC and POPE lipids) and liquid-condensed (LC; rich in SM lipid) phases, as previously observed ${ }^{65}$ (Figure S6). By compressing the monolayer to $\pi=30$ $\mathrm{mN} \mathrm{m}^{-1}$ we can achieve an area per lipid representative of lipid packing within a cell membrane.

Interfacial tensions are often reported to decrease with time as proteins or proteinnanoparticle complexes penetrate into a lipid monolayer and fill void space between lipids at the air-water interface. ${ }^{88}$ We observed this for initial surface pressures less than $10 \mathrm{mN} \mathrm{m}^{-1}$ where A $\geq 82 \AA^{2}$ molecule $^{-1}$ (Figure S6). However, increases in interfacial tension were observed for HSA (Figure S6; shown as decreases in $\pi$ ) and for NP and NP-HC complexes (Figure 5A1-C1) at an initial surface pressure of $30 \mathrm{mN} \mathrm{m}^{-1}$. We measured the surface concentrations of PS and PS-HC complexes that produced the increases in interfacial tension. Based on the relative concentrations with and without an RBC monolayer present, $\Gamma_{+R B C} / \Gamma_{-R B C}$ (Figure 3B), the monolayer reduced the amount of bare PS nanoparticles at the air-lipid-water interface by $80 \%$ (PS, PS-COOH) and 
$50 \%$ (PS-NH), which correlates to a $\Theta_{\infty}$ of approximately 0.07 (PS), 0.1 (PS-COOH), and 0.24

(PS-NH). Comparatively, particles with protein coronas showed a high degree of surface coverage similar to when no lipid monolayer was present.

BAM imaging was conducted at early $\left(10^{3} \mathrm{~s}\right)$ and late $\left(10^{4} \mathrm{~s}\right)$ times as the NPs and NP$\mathrm{HC}$ complexes adsorbed to and interacted with the lipid monolayer (Figure 5A2-C2). Coexisting LE-LC phases are observed at early times for NPs with and without formed coronas. Bare NPs accumulate at the interface and appear to thicken LC domains (some free, lighter grey LC domains are still observed). For anionic PS and PS-COOH, binding is consistent with electrostatic and charge-dipole interactions with LC domains, where the lipid dipole moment extends perpendicular to the air-water interface with the positively charged choline headgroup extending into the aqueous subphase..$^{33,89-91}$ For cationic PS-NH, large fractal aggregates of NPs are observed, reflecting the greater measured surface coverage, $\Theta_{\infty}$ (Figure 5C2). Unlike anionic NPs, cationic NPs have been shown to preferential bind to LE phases where the lipid headgroup dipole is parallel to the interface and the negatively charged phosphate group is accessible. ${ }^{92}$ Therefore, we attribute the structures formed with PS-NH to NP binding primarily to the LE phase followed by NP aggregation. Free LC domains remain present throughout the process.

The presence of a HC, where hydrophobic interactions between HSA and zwitterionic lipids are dominant, led to the formation of unique structures composed of clustered LC domains at early times, and a thick interfacial layer similar to HSA at the air-lipid-water interface at pseudo-equilibrium. Interactions between HSA and zwitterionic lipid monolayers have been shown to decrease with increasing lipid packing (lower area per lipid), ${ }^{93}$ suggesting that the NP$\mathrm{HC}$ complexes preferentially bind to the LE phase. Given the high surface coverage of the corona complexes at the air-lipid-water interface and the observed aggregation behavior at the 
air-water interface Figure 2), we ascribe the clustering of LC domains to these domains being excluded from LE domains with bound aggregates of NP-HC complexes.
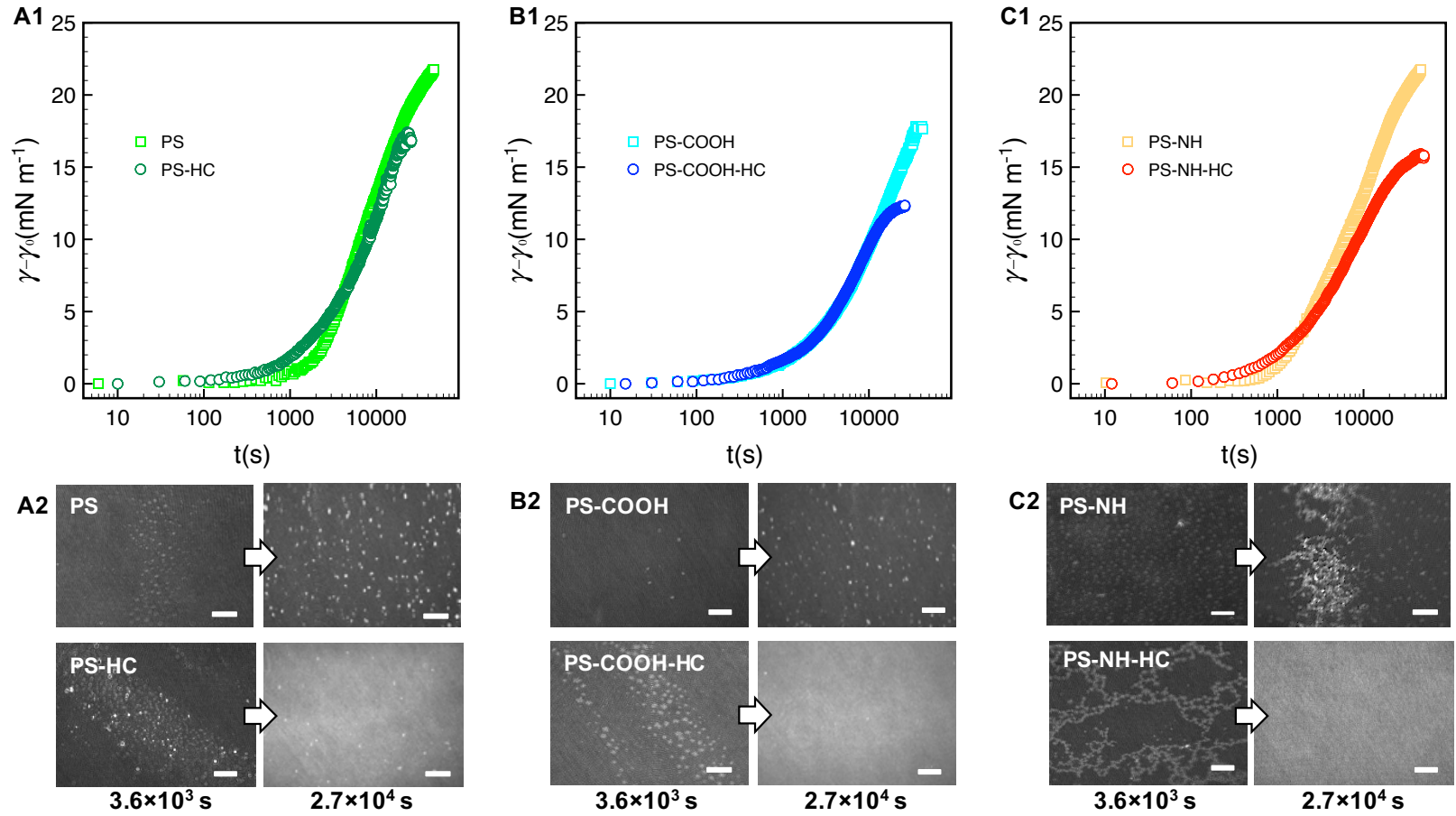

Figure 5. Dynamic changes in interfacial tension for (A1) PS, (B1) PS-COOH, and (C1) PS-NH nanoparticles before and after complexation with HSA, plotted in a semi-logarithm scale.

Corresponding BAM images are shown in A2-C2 at early $\left(10^{3} \mathrm{~s}\right)$ and late $\left(10^{4} \mathrm{~s}\right)$ times during the adsorption process.

The significant difference in surface coverage between bare and corona-complexed NPs, and distinct differences in interfacial structure, suggests that different mechanisms are at play. Bare NPs appear to have preferentially bound to LC or LE phases, adsorbing lipids and partially removing them from the interface, while NP-HC complexes and the lipids remained an integral part of the interfacial layer. Di Silvio et al. ${ }^{68}$ showed that bare $100 \mathrm{~nm}$ PS-COOH NPs disrupted a zwitterionic supported lipid bilayer by lipid extraction. Bilayer disruption was observed when 
the particles were coated with a soft protein corona of fetal bovine serum, but not a hard corona. This was attributed to the weakly bound soft corona proteins (or free proteins) acting in concert with the NPs on the membrane surface. Our results demonstrating that the NP-HC complexes disrupt monolayers and that $\mathrm{HC}$ proteins drive this disruption may reflect the different protein used (HSA vs FBS) and the more fluid nature of a monolayer. Out of plane distortions are more restricted in a supported lipid monolayer that is adsorbed onto a solid surface.

Surface pressure-area isotherms were generated under compression for the lipid monolayers with NP-HC complexes (Figure 6A). The RBC monolayer exhibited an continuous increase in $\pi$ with decreasing area, the nucleation of LC domains between 10 to $15 \mathrm{mN} \mathrm{m}^{-1}$ (bright spots at $\pi \geq 15 \mathrm{mN} \mathrm{m}^{-1}$ in BAM images; Figure 6C), and the growth of the LC domains up to $35 \mathrm{mN} \mathrm{m}^{-1}$. With the addition of HSA the isotherm resembles that of HSA alone at the airwater interface, with hydrophilic residues expelled from the interface at a slightly higher surface pressure $\left(\pi=15 \mathrm{mN} \mathrm{m}^{-1}\right.$ compared to $\left.12 \mathrm{mN} \mathrm{m}^{-1}\right)$. LC domains were not observed, and the structure of the layer was again visually similar to HSA alone based on reflectance (Figures 4D, 6D). These results indicate that the interface was comprised of HSA-lipid complexes, with these complexes being "squeezed out" of the monolayer at high surface pressures. The reversibility of the compression-expansion isotherms (data not shown) suggests that the displaced complexes remain near the interface and re-adsorbed at low surface pressures, consistent with previous results for bovine serum albumin and zwitterionic phosphatidyldimethylethanolamine. ${ }^{94}$

With NP-HC complexes the intrinsic behavior of the proteins driving the surface activity and compressibility of the complexes at an air-water interface is also observed at an air-lipidwater interface. Transitions in surface pressure between $20-25 \mathrm{mN} \mathrm{m}^{-1}$ due to hydrophilic residues being expelled from the interface are observed for NP-HC complexes. The 
conformational changes in corona proteins at the air-water interface also occur at the air-lipidwater interface. Maximum $C^{-1}$ values were $103 \mathrm{mN} \mathrm{m}^{-1}$ for the lipid monolayer, consistent with previous results for a model RBS outer membrane leaflet, ${ }^{63} 52 \mathrm{mN} \mathrm{m}^{-1}$ when exposed to HSA, and ranged from $46-51 \mathrm{mN} \mathrm{m}^{-1}$ for mixed layers of lipid+NP complexes. The presence of lipid added additional compressibility compared to the air-water interface, however the values were similar to HSA alone.
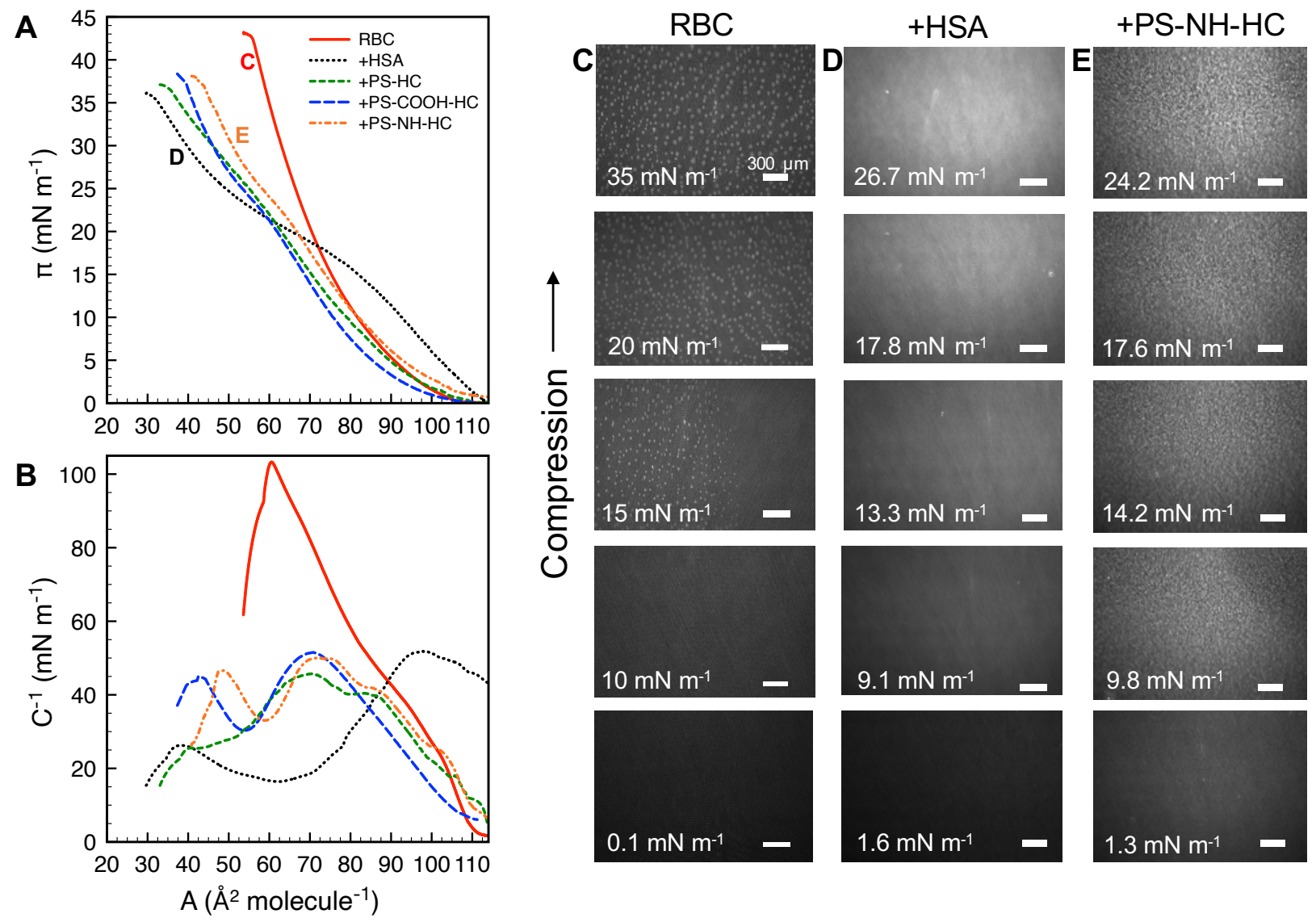

Figure 6. Surface pressure-area isotherms (A) and inverse compressibility moduli (B) of the RBC monolayer alone and exposed to HSA and the NP-HC complexes. Corresponding BAM images are shown for (BC) the RBC monolayer exposed to (D) HSA or (E) PS-NH-HC. Scale bars in C-E represent $300 \mu \mathrm{m}$. 
BAM images for PS-NH-HC are shown in Figure 6E (PS-HC and PS-COOH-HC led to the same structures and are not shown). Small, bright spots are observed at $\pi \geq 9.8 \mathrm{mN} \mathrm{m}^{-1}$ and become larger with compression. This is attributed to the increasing displacement of lipid/PS complexes into the air, whereas HSA-lipid complexes are displaced into the aqueous phase. The displacement of lipid/PS complexes above the interface may be due to adsorbed lipids rendering them more hydrophobic. Therefore, the increases in dynamic interfacial tension observed in Figure 5 are likely due to the formation of lipid/PS complex and the displacement behavior rather than lipid condensation, which has been previously reported for charged nanoparticles interacting with zwitterionic lipid monolayers or bilayers. ${ }^{33,89-91}$

\section{Conclusions}

Surface pressure measurements were coupled with fluorescence and Brewster angle microscopy to investigate the effects of a serum protein corona on the intrinsic surface activity of charged polystyrene nanoparticles and on the interactions with a model human red blood cell (RBC) lipid monolayer. We show that 'classic' theoretical models can capture the adsorption kinetics of bare and corona-complexed NPs, and the additional particle trapping energies associated with protein denaturing, which was confirmed experimentally. The ability for proteins within a corona to denature infers an additional driving force for nanoparticle-corona complexes to adhere to biological interfaces. This was further observed with the lipid monolayer present for all NP-HC complexes examined, suggesting that the protein corona controlled monolayer adhesion. Interestingly, the lipid monolayer prevented the majority of the bare nanoparticles from adsorbing at the interface (compared to an air-water interface), but was able to accommodate most of the NP-HC complexes because of their appreciable surface activity. In 
addition to the surface activity, this may reflect the affinity of HSA for the lipids - HSA binds and transports fatty acids through the bloodstream. We should point out that, while other studies with serum coronas have shown similar features, ${ }^{50,94}$ this work represents an initial demonstration of the interfacial interactions that occur when nanoparticle-HSA corona complexes interact with a model lipid monolayer. We expect that the surface activity-based approach may translate more broadly to other nanoparticle-protein corona complexes.

\section{Conflicts of interest}

There are no conflicts to declare

\section{Acknowledgments}

This material is based upon work supported by the National Science Foundation (NSF) under Grant No. CBET-1055652. Additional resources were provided by the Rhode Island Center for Nanoscience and Nanotechnology, which is supported by RI NSF EPSCoR under Grant No. OIA-1655221. We thank Dr. Irene Andreu in the Department of Chemical Engineering at URI for assisting with TEM imaging.

\section{REFERENCES}

1 S. Kihara, N. J. Van Der Heijden, C. K. Seal, J. P. Mata, A. E. Whitten, I. Köper and D. J. McGillivray, Bioconjug. Chem., 2019, 30, 1067-1076.

2 S. Lambert and M. Wagner, Chemosphere, 2016, 145, 265-268.

3 A. Cózar, F. Echevarría, J. I. González-Gordillo, X. Irigoien, B. Ubeda, S. HernándezLeón, A. T. Palma, S. Navarro, J. García-de-Lomas, A. Ruiz, M. L. Fernández-de-Puelles 
and C. M. Duarte, Proc. Natl. Acad. Sci. U. S. A., 2014, 111, 10239-44.

4 H. Bouwmeester, P. C. H. Hollman and R. J. B. Peters, Environ. Sci. Technol., 2015, 49, $8932-8947$.

5 A. Rajeev, V. Erapalapati, N. Madhavan and M. G. Basavaraj, J. Appl. Polym. Sci., 2016, $133,2-6$.

6 J. Costa, P. S. M. Santos, A. C. Duarte and T. Rocha-santos, Sci. Total Environ., 2016, 566-567, 15-26.

7 A. L. Dawson, S. Kawaguchi, C. K. King, K. A. Townsend, R. King, W. M. Huston and S. M. Bengtson Nash, Nat. Commun., 2018, 9, 1-8.

8 Y. Chae and Y. J. An, Environ. Pollut., 2018, 240, 387-395.

9 M. Carbery, W. Andrew O'connor, T. Palanisami, W. O'connor and P. Thavamani, Environmemt Int., 2018, 115, 400-409.

10 M. Smith, D. C. Love, C. M. Rochman and R. A. Neff, Curr. Environ. Heal. reports, $2018,5,375-386$.

11 A. D. Vethaak and H. A. Leslie, Environ. Sci. Technol., 2016, 50, 6825-6826.

12 J. Pinto, P. S. M. Santos, A. C. Duarte and T. Rocha-santos, 2016, 567, 15-26.

13 R. H. Waring, R. M. Harris and M. C., 2018, 115, 64-68.

14 M. Revel, A. Chatel and C. Mouneyrac, Curr. Opin. Environ. Sci. Heal., 2018, 1, 17-23.

15 R. R. Hurley and L. Nizzetto, Curr. Opin. Environ. Sci. Heal., 2018, 1, 6-11.

16 K. D. Cox, G. A. Covernton, H. L. Davies, J. F. Dower, F. Juanes and S. E. Dudas, Environ. Sci. Technol., , DOI:10.1021/acs.est.9b01517.

17 A. M. Farnoud and S. Nazemidashtarjandi, Environ. Sci. Nano, 2019, 6, 13-40.

18 C. Loos, T. Syrovets, A. Musyanovych, V. Mailänder, K. Landfester, G. Ulrich Nienhaus 
and T. Simmet, Beilstein J. Nanotechnol., 2014, 5, 2403-2412.

19 E. Guzmán and E. Santini, Curr. Opin. Colloid Interface Sci., 2019, 39, 24-39.

20 E. G. E. Ragnarsson and E. Gullberg, 2005, 25, 455-465.

21 J. Cabellos, C. Delpivo, E. Fernández-Rosas, S. Vázquez-Campos and G. Janer, NanoImpact, 2017, 5, 51-60.

22 K. E. Carr, S. H. Smyth, M. T. Mccullough, J. F. Morris and S. M. Moyes, , DOI:10.1016/j.proghi.2011.11.001.

23 G. F. Schirinzi, I. Pérez-Pomeda, J. Sanchís, C. Rossini, M. Farré and D. Barceló, Environ. Res., 2017, 159, 579-587.

24 D. M. Brown, M. R. Wilson, W. MacNee, V. Stone and K. Donaldson, Toxicol. Appl. Pharmacol., 2001, 175, 191-199.

25 H. Makkar, S. K. Verma, P. K. Panda, N. Pramanik, E. Jha and M. Suar, 2018, 959-969.

26 A. K. Sachan, R. K. Harishchandra, C. Bantz, M. Maskos, R. Reichelt and H. J. Galla, ACS Nano, 2012, 6, 1677-1687.

27 R. K. Harishchandra, A. K. Sachan, A. Kerth, G. Lentzen, T. Neuhaus and H. J. Galla, Biochim. Biophys. Acta - Biomembr., 2011, 1808, 2830-2840.

28 S. Nazemidashtarjandi and A. M. Farnoud, Environ. Sci. Nano, 2019, 6, 1219-1232.

29 Y. Chen and G. D. Bothun, Langmuir, 2009, 25, 4875-4879.

30 A. Xi and G. D. Bothun, Analyst, 2014, 139, 973-981.

31 N. Ganji, I. A. Khan and G. D. Bothun, Langmuir, , DOI:10.1021/acs.langmuir.7b03743.

32 N. M. Anaya, F. Faghihzadeh, N. Ganji, G. Bothun and V. Oyanedel-craver, 2016, 565, $841-848$.

33 G. D. Bothun, N. Ganji, I. A. Khan, A. Xi and C. Bobba, Langmuir, 2017, 33, 353-360. 
34 E. Guzmán, M. Ferrari, E. Santini, L. Liggieri and F. Ravera, Colloids Surfaces B Biointerfaces, 2015, 136, 971-980.

35 E. Guzmán, L. Liggieri, E. Santini, M. Ferrari and F. Ravera, Colloids Surfaces A Physicochem. Eng. Asp., , DOI:10.1016/j.colsurfa.2011.12.059.

36 K. L. Chen and G. D. Bothun, Environ. Sci. Technol., 2014, 48, 873-880.

37 Q. Wang, M. Lim, X. Liu, Z. Wang and K. L. Chen, Environ. Sci. Technol., 2016, 50, 2301-2309.

38 S. Schöttler, K. Klein, K. Landfester and V. Mailänder, Nanoscale, 2015, 00, 1-3.

39 I. Lynch, A. Salvati and K. A. Dawson, Nat. Nanotechnol., 2009, 4, 546-547.

40 C. el al Claudia, Nanomedicine, 2015, 11, 81-100.

41 R. D. Vinluan and J. Zheng, Nanomedicine, 2015, 10, 2781-2794.

42 G. Hu, B. Jiao, X. Shi, R. P. Valle, Q. Fan and Y. Y. Zuo, ACS Nano, 2013, 7, $10525-$ 10533.

43 M. P. Monopoli, C. Åberg, A. Salvati and K. A. Dawson, Nat. Nanotechnol.,, DOI:10.1038/nnano.2012.207.

44 D. Docter, D. Westmeier, M. Markiewicz, S. Stolte, S. K. Knauer and R. H. Stauber, Chem. Soc. Rev., , DOI:10.1039/c5cs00217f.

45 V. H. Nguyen and B. J. Lee, Int. J. Nanomedicine, 2017, 12, 3137-3151.

46 S. Milani, F. Baldelli Bombelli, A. S. Pitek, K. A. Dawson and J. Rädler, ACS Nano, , DOI:10.1021/nn204951s.

47 K. A. Dawson, A. Lesniak, F. Fenaroli, M. P. Monopoli, A. Christoffer and A. Salvati, ACS Nano, 2012, 6, 5845-5847.

48 J. R. Lawrence, G. D. W. Swerhone, J. J. Dynes, A. P. Hitchcock and D. R. Korber, 
Environ. Sci. Nano, , DOI:10.1039/C5EN00229J.

49 C. Eudald, P. Tobias, D. Albert, O. Gertie Janneke and P. Victor, ACS Nano, 2010, 4, $3623-3632$.

50 E. S. Melby, S. E. Lohse, J. E. Park, A. M. Vartanian, R. A. Putans, H. B. Abbott, R. J. Hamers, C. J. Murphy and J. A. Pedersen, ACS Nano, , DOI:10.1021/acsnano.7b00231.

51 S. Dominguez-Medina, L. Kisley, L. J. Tauzin, A. Hoggard, B. Shuang, A. S. D. S. Indrasekara, S. Chen, L.-Y. Wang, P. J. Derry, A. Liopo, E. R. Zubarev, C. F. Landes and S. Link, ACS Nano, , DOI:10.1021/acsnano.5b06439.

52 S. Dominguez-Medina, J. Blankenburg, J. Olson, C. F. Landes and S. Link, ACS Sustain. Chem. Eng., 2013, 1, 833-842.

53 P. C. Ke, S. Lin, W. J. Parak, T. P. Davis and F. Caruso, ACS Nano, 2017, 11, 1177311776.

54 K. Serre, L. Giraudo, L. Leserman and P. Machy, Methods Enzymol., 2003, 373, 100-118.

55 S. Nagayama, K. ichi Ogawara, Y. Fukuoka, K. Higaki and T. Kimura, Int. J. Pharm., 2007, 342, 215-221.

56 B. D. Chithrani, A. A. Ghazani and W. C. W. Chan, Nano Lett., 2006, 6, 662-668.

57 D. Guarnieri, A. Guaccio, S. Fusco and P. A. Netti, J. Nanoparticle Res., 2011, 13, 42954309.

58 Y. Zhu, W. Li, Q. Li, Y. Li and Y. Li, 2009, 7, 3-10.

59 X. Jiang, S. Weise, M. Hafner and C. Ro, .

60 P. C. Patel, D. A. Giljohann, W. L. Daniel, D. Zheng, A. E. Prigodich and C. A. Mirkin, 2010, 13, 2250-2256.

61 I. Stayton, J. Winiarz, K. Shannon and Y. Ma, Anal. Bioanal. Chem., 2009, 394, 1595- 
1608.

62 A. Lesniak, A. Salvati, M. J. Santos-Martinez, M. W. Radomski, K. A. Dawson and C. Åberg, J. Am. Chem. Soc., 2013, 135, 1438-1444.

63 M. Arczewska, G. Czernel and M. Gagoś, J. Phys. Chem. B, 2016, 120, 11191-11204.

64 K. Hạc-Wydro and P. Dynarowicz-ŁA̧tka, Biochim. Biophys. Acta-Biomembr., 2012, 1818, 2184-2191.

65 P. Wydro, Colloids Surfaces B Biointerfaces, 2013, 103, 67-74.

66 J. A. Virtanen, K. H. Cheng and P. Somerharju, Proc. Natl. Acad. Sci. U. S. A., 1998, 95, 4964-9.

67 Y. Yawata, Cell Membrane: The Reb Blood Cell as a Model, Wiley, 2003.

68 D. Di, M. Maccarini, R. Parker, A. Mackie, G. Fragneto and F. Baldelli, J. Colloid Interface Sci., 2017, 504, 741-750.

69 D. Di Silvio, N. Rigby, B. Bajka, A. Mayes, A. Mackie and F. Baldelli Bombelli, Nanoscale, 2015, 7, 11980-11990.

70 J. B. Sheffield, Microsc. Microanal., 2008, 14, 898-899.

71 S. Yu, A. Perálvarez-Marín, C. Minelli, J. Faraudo, A. Roig and A. Laromaine, Nanoscale, 2016, 8, 14393-14405.

72 M. Kokkinopoulou, J. Simon, K. Landfester, V. Mailänder and I. Lieberwirth, Nanoscale, 2017, 9, 8858-8870.

73 P. Renz, M. Kokkinopoulou, K. Landfester and I. Lieberwirth, Macromol. Chem. Phys., 2016, 217, 1879-1885.

74 A. Adamiano, I. G. Lesci, D. Fabbri and N. Roveri, J. R. Soc. Interface,, DOI:10.1098/rsif.2015.0186. 
75 L. F. Chi, M. Anders, H. Fuchs, R. R. Johnston and H. Ringsdorf, Science (80-. )., 1993, 259, 213-216.

76 X. Min and Daniel C, Nature, 2015, 360, 40-46.

77 X. Lin, A. A. Gorfe and I. Levental, Biophys. J., 2018, 114, 1936-1944.

78 P. Toimil, G. Prieto, J. Miñones, J. M. Trillo and F. Sarmiento, Colloids Surfaces B Biointerfaces, 2012, 92, 64-73.

79 V. Garbin, J. C. Crocker and K. J. Stebe, J. Colloid Interface Sci., 2012.

80 K. Du, E. Glogowski, T. Emrick, T. P. Russell and A. D. Dinsmore, Langmuir, 2010, 26, $12518-12522$.

81 A. F. H. Ward and L. Tordai, J. Chem. Phys., 1946, 14, 453-461.

82 N. Bizmark, M. A. Ioannidis and D. E. Henneke, Langmuir, 2014, 30, 710-717.

83 M. Flury and S. Aramrak, Water Resour. Res., 2017, 53, 5247-5275.

84 M. Manciu and E. Ruckenstein, Colloids Surfaces A Physicochem. Eng. Asp., 2012, 400, $27-35$.

85 C. Tian, J. Feng, H. J. Cho, S. S. Datta and R. K. Prud'homme, Nano Lett., 2018, 18, 4854-4860.

86 Z. Adamczyk, J. Colloid Interface Sci., 2000, 229, 477-489.

87 J. Sánchez-González, J. Ruiz-García and M. J. Gálvez-Ruiz, J. Colloid Interface Sci., , DOI:10.1016/S0021-9797(03)00754-9.

88 S. M. Lystvet, S. Volden, Ø. Halskau and W. R. Glomm, Soft Matter, 2011, 7, 1150111509.

89 A. C. Mensch, J. T. Buchman, C. L. Haynes, J. A. Pedersen and R. J. Hamers, Langmuir, 2018, 34, 12369-12378. 
90 A. M. Farnoud and J. Fiegel, J. Phys. Chem. B, 2013, 117, 12124-12134.

91 B. Wang, L. F. Zhang, S. C. Bae and S. Granick, Proc. Nat. Acad. Sci. USA, 2008, 105, $18171-18175$.

92 T. Wang, X. Hu and S. Dong, 2008, 781-786.

93 X. Wang, Y. Zhang, J. Wu, M. Wang, G. Cui, J. Li and G. Brezesinski, Colloids Surfaces B Biointerfaces, 2002, 23, 339-347.

94 N. C. de Souza, W. Caetano, R. Itri, C. A. Rodrigues, O. N. Oliveira, J. A. Giacometti and M. Ferreira, J. Colloid Interface Sci., 2006, 297, 546-553. 


\title{
Supporting Information for
}

Serum proteins coronas render nanoparticles surface active: Consonant interactions at air-water and at lipid monolayer interfaces

\author{
Nasim Ganji ${ }^{1}$ and Geoffrey D. Bothun ${ }^{1, *}$ \\ ${ }^{1}$ Department of Chemical Engineering, University of Rhode Island, 303 Fascitelli Engineering \\ Building, 2 East Alumni Ave, Kingston, RI 02881, United States
}

*Corresponding author. Tel: +1-401-874-9518, E-mail: gbothun@uri.edu

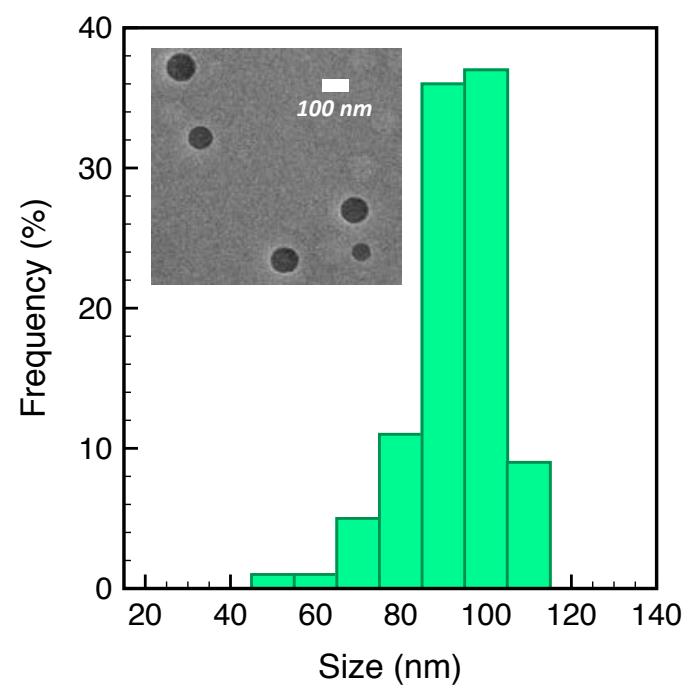

Figure S1. Histogram plot of PS NPs core diameter, $d_{c}$, based on TEM analysis (inset: a representative micrograph). The core radius $\left(d_{c}\right)$ of the NPs was determined by analyzing TEM images with the ImageJ software $(n>50)$.

Computational visualization of HSA. The atomic structure of HSA was based on crystal structure 1UOR in the Protein Data Bank. The online tool PROPKA was used to determine the protonation state of ionizable groups at $\mathrm{pH}$ 7.4. $\mathrm{PDB} 2 \mathrm{PQR}$ was then used to determine the charge of each atom within the protein. ${ }^{1}$ With the software Visual Molecular Dynamics, the 3- 
dimentional structure of HSA was rendered depicting the location of acidic (blue), basic (red), polar (yellow), and hydrophobic (silver) amino acid residues (Figure S2).

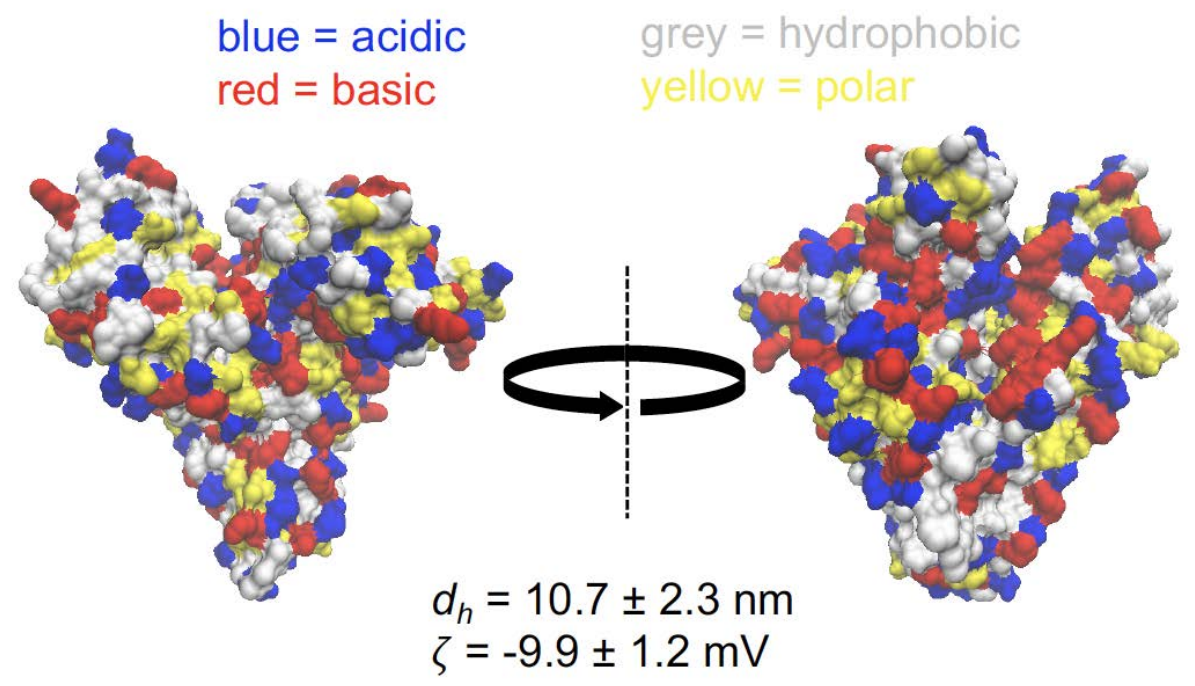

Figure S2. Computed structure of HSA at pH 7.4 depicting the location of acidic (blue), basic (red), polar (yellow), and hydrophobic (silver) amino acid residues. The hydrodynamic diameter (dh) zeta potential () in $\mathrm{pH} 7.4$ PBS are also shown. This image was made with VMD/NAMD/BioCoRE/JMV/other software support. VMD/NAMD/BioCoRE/JMV/ is developed with NIH support by the Theoretical and Computational Biophysics group at the Beckman Institute, University of Illinois at Urbana-Champaign. 

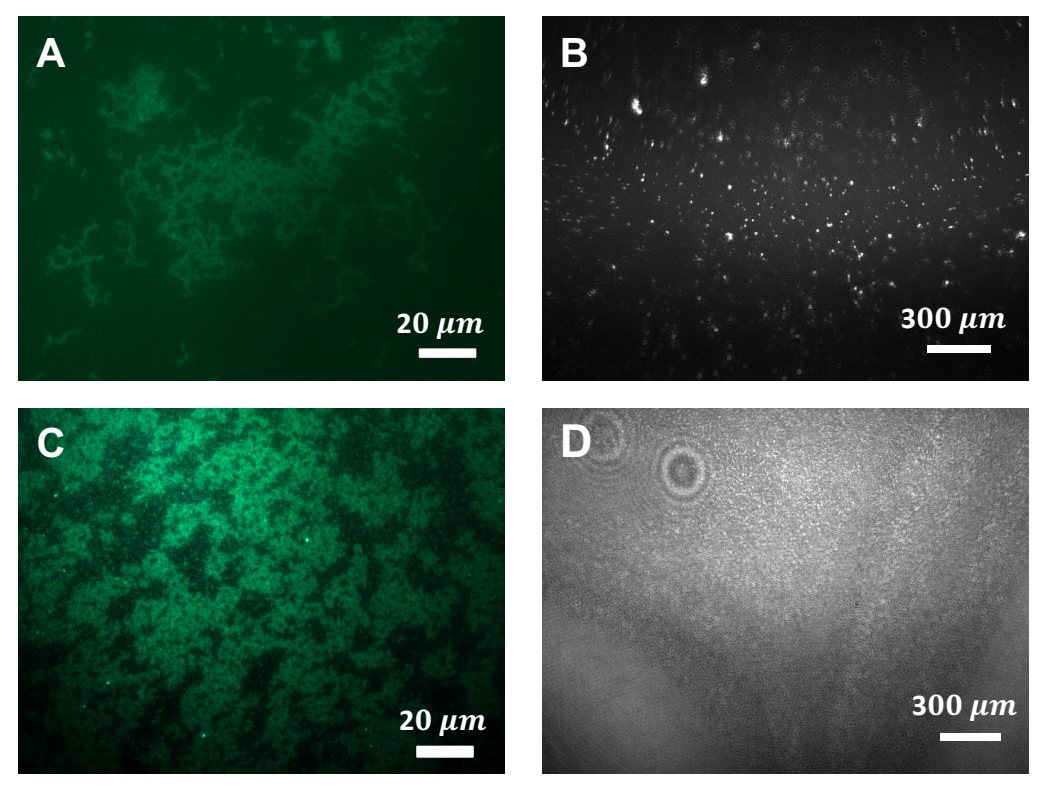

Figure S3. Representative fluorescence (A, C) and Brewster Angle (B, D) microscopy images of PS-NH nanoparticles (A, B) and PS-NH-HC complexes (C, D) at the air-water interface.

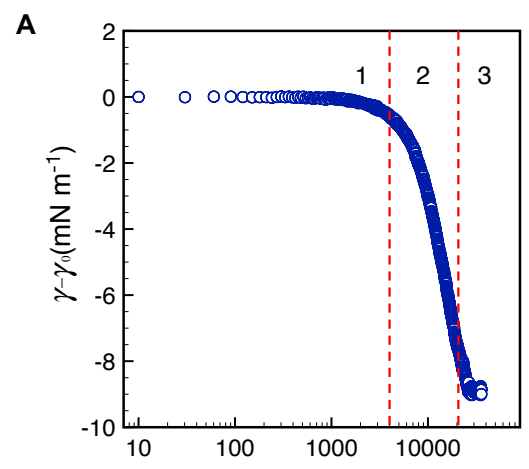

$\mathrm{t}(\mathrm{s})$
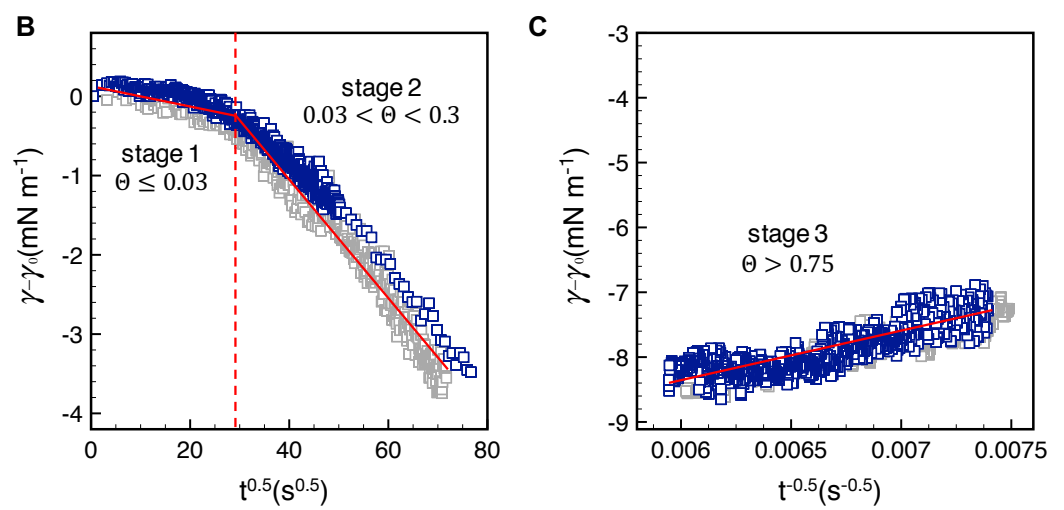

Figure S4. (A) Dynamic changes in interfacial tension, $\gamma-\gamma_{0}$, for PS-COOH-HC complexes, where three stages of behavior are displayed. In (B) $\gamma-\gamma_{0}$ is plotted as a function of $t^{0.5}$ at early times where the adsorption is diffusion-controlled; and in $(\mathrm{C})$ as a function of $t^{-0.5}$, during the later stage of adsorption when it is barrier-controlled. Duplicate experiments are shown in (B) and (C) with grey and blue symbols. Dashed red lines denote the transition between stages and solid red lines represent linear line fits for each stage. 

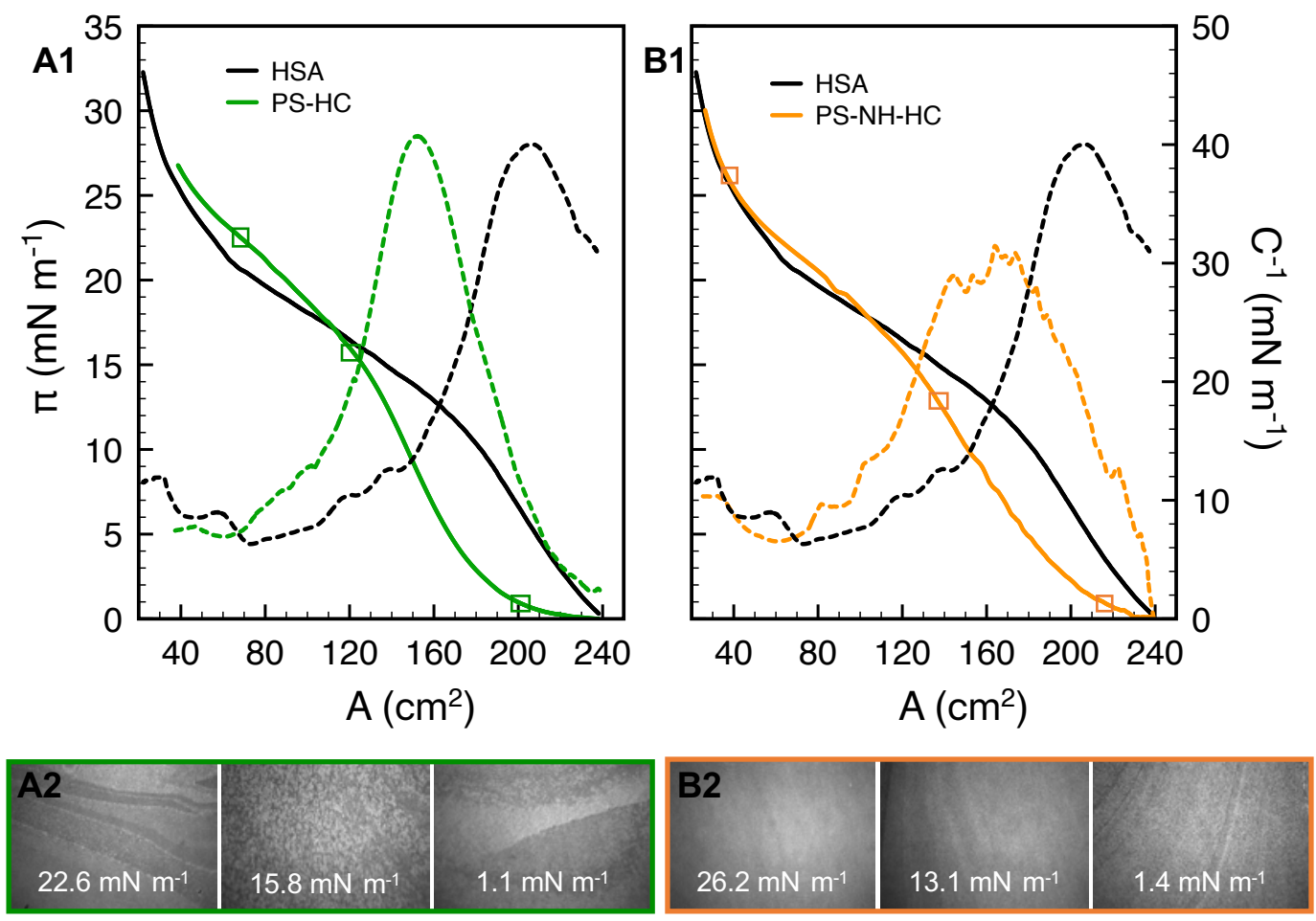

Figure S5. Surface pressure-area isotherms $(\pi-A)$ and corresponding inverse compressibility moduli $\left(C^{-1}\right)$ for HSA, (A1) PS-HC, and (B1) PS-NH-HC at the air-water interface. The open squares shown on the isotherms denote the conditions for BAM imaging shown in $\mathrm{A} 2$ and $\mathrm{B} 2$.

RBC monolayer morphology and $\boldsymbol{\pi}-\mathbf{A}$ isotherm. Surface pressure-area isotherm of the mixed lipid film mimicking the outer leaflet of human RBC membrane is shown in Figure S5A. Increasing $\pi$ corresponded to a decrease in $A$ with compression as the lipids packed more tightly at the interface. There was a continuous phase transition from the gaseous $(\mathrm{G})$-phases at large lipid molecular area $\left(\mathrm{A} \approx 113 \AA^{2}\right.$ molecule $\left.^{-1}\right)$ to coexisting liquid-expanded $(\mathrm{LE})$ and liquidcondensed (LC) phases at lower lipid molecular area where $\pi \geq 15 \mathrm{mN} \mathrm{m}^{-1}$, with the monolayer 
collapse occurring at $\pi \approx 43 \mathrm{mN} \mathrm{m}^{-1}$. The morphology of the film was visualized in situ using Brewster angle microscopy (BAM) technique. The BAM images were taken throughout the monolayer compression isotherm at $23^{\circ} \mathrm{C}$. Representative fluorescence and Brewster angle microscopy images of the monolayers are shown in Figure S5B. The morphology of the films is comparable to that reported previously in the literature for the same lipid system. ${ }^{2-4} \mathrm{RBC}$ monolayers existed as $\mathrm{G}$ phases at $\pi=0.1 \mathrm{mN} \mathrm{m}^{-1}$ and mixed of two LE phases at $\pi=10 \mathrm{mN}$ $\mathrm{m}^{-1}$. First domains of LC phases appeared at $\pi=15 \mathrm{mN} \mathrm{m}^{-1}$. These domains existed up to the collapse point, while they enlarged with further compression and took a flower-like characteristic of pure SM monolayer.
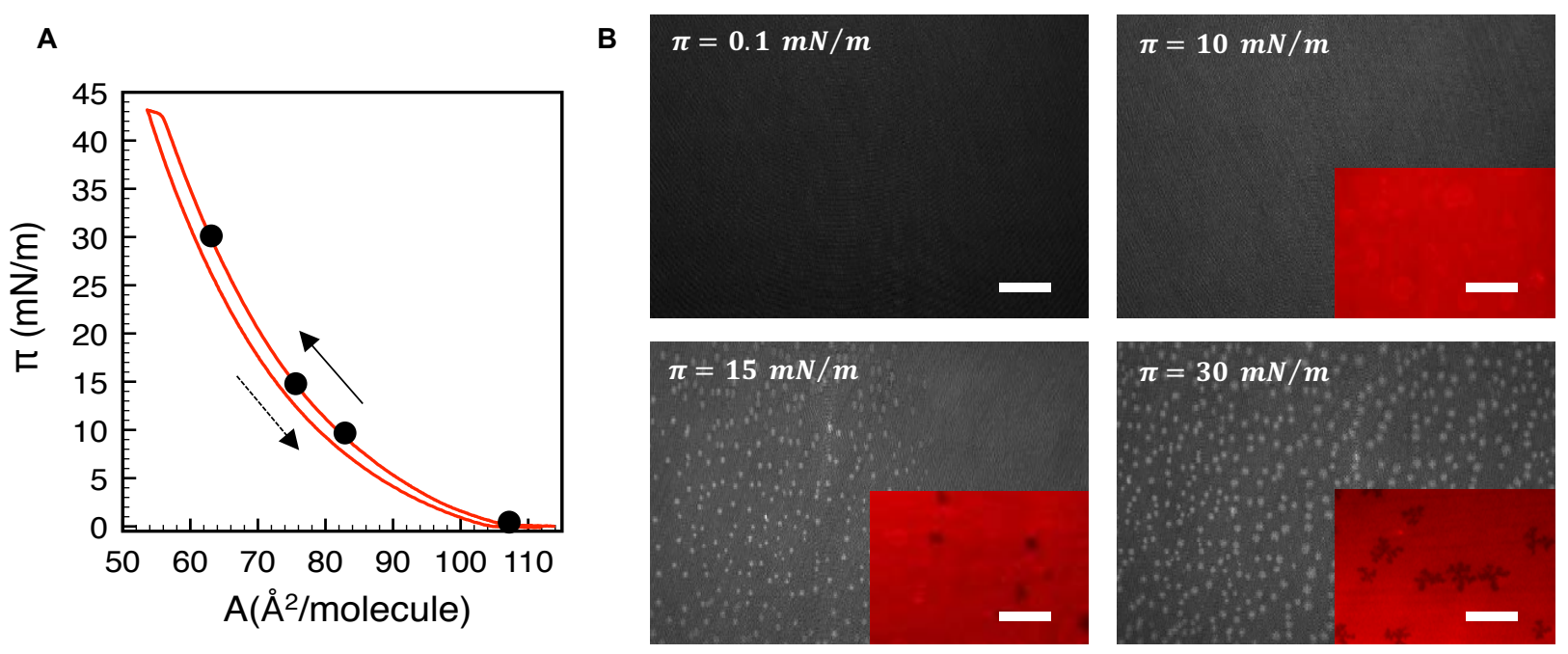

Figure S5. (A) Surface pressure-area $(\pi-A)$ isotherm of the monolayer at the air-water interface at $23{ }^{\circ} \mathrm{C}$. Arrows indicate compression (solid line) followed by expansion (dashed line). (B) Representative fluorescence microscopy $($ Scale bars $=20 \mu \mathrm{m})$ and BAM images (Scale bars $=300$ $\mu \mathrm{m})$ of the film during a compression isotherm. 


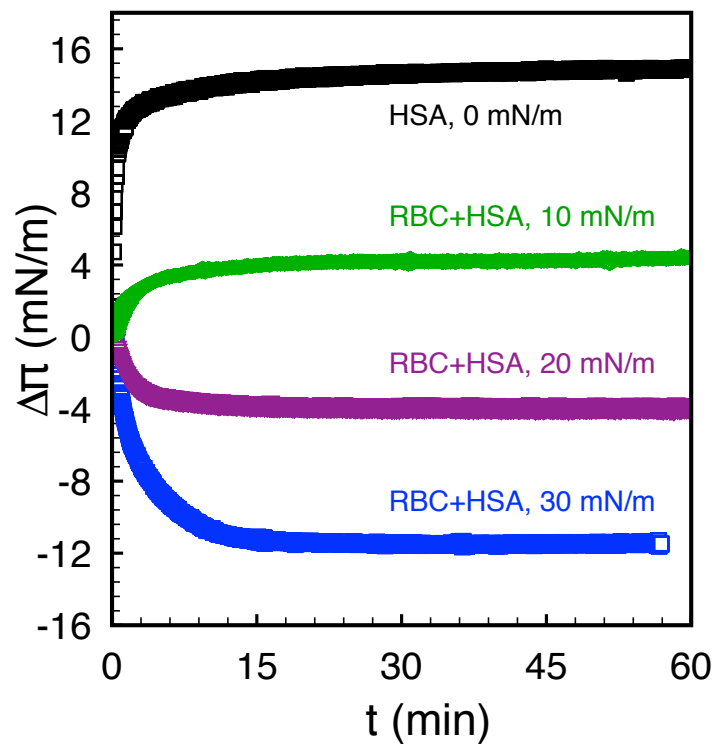

Figure S6. Change in surface pressure $(\Delta \pi)$ during HSA adsorption to the air-water interface $(0$ $\mathrm{mN} / \mathrm{m}$ ) and to air-lipid-water interfaces formed with RBC outer leaflet lipids pre-compressed to surface pressures of 10,20 , or $30 \mathrm{mN} / \mathrm{m}$.

\section{REFERENCES}

1 T. J. Dolinsky, J. E. Nielsen, J. A. McCammon and N. A. Baker, Nucleic Acids Res., , DOI:10.1093/nar/gkh381.

2 K. Hạc-Wydro and P. Dynarowicz-ŁA̧tka, Biochim. Biophys. Acta-Biomembr., 2012, 1818, 2184-2191.

3 P. Wydro, Colloids Surfaces B Biointerfaces, 2013, 103, 67-74.

4 M. Arczewska, G. Czernel and M. Gagoś, J. Phys. Chem. B, 2016, 120, 11191-11204. 